\title{
ANÁLISIS DE LA EVOLUCIÓN CONSTRUCTIVA DE LAS ESTRUCTURAS EXCAVADAS EN EL YACIMIENTO DE A CIDADELA (SOBRADO DOS MONXES, A CORUÑA) Y PROPUESTAS INTERPRETATIVAS SOBRE SUS "FASES TARDOANTIGUAS"
}

\author{
REBECA BLANCO-ROTEA ${ }^{(1)}$, JOSÉ MANUEL COSTA GARCÍA ${ }^{(2)} \&$ JOSÉ CARLOS SÁNCHEZ-PARDO $^{(3)}$
}

Resumen:

\begin{abstract}
Se presentan los resultados del estudio llevado a cabo en el yacimiento de A Cidadela (Sobrado dos Monxes, A Coruña) en el marco del proyecto Marie Curie Early Medieval Churches: History, Archaeology and Heritage (EMCHAHE). Este yacimiento comprende los restos de un recinto militar romano de los siglos II-III d.C. y sucesivas ocupaciones de épocas tardoantigua y altomedieval, todavía poco conocidas. El estudio presentado se basa en un enfoque interdisciplinar que combina por primera vez una revisión de todo el material generado a partir de las distintas excavaciones arqueológicas pre-estratigráficas y estratigráficas llevadas a cabo en el yacimiento, con la lectura estratigráfica de paramentos. En esta revisión se ha hecho especial hincapié en la reocupación del fuerte en época tardoantigua y especialmente en una serie de estructuras identificadas como posible iglesia. Pese a que se trata de resultados preliminares, los datos obtenidos permiten hablar de una fase de reocupación mucho más importante en todo este recinto de lo pensado hasta el momento. En base a estos resultados, se realiza una valoración del papel de este yacimiento en el contexto del conocimiento actual sobre la Tardoantigüedad en Galicia.
\end{abstract}

Palabras clave: Fuerte romano, Época altomedieval, Galicia tardoantigua, Interdisciplinaridad, Lectura estratigráfica de paramentos, Arqueología medieval

\begin{abstract}
:
Constructive sequence analysis of the excavated structures of A Cidadela site (Sobrado dos Monxes, A Coruña) and interpretative proposals on its "late antique phases"

This paper presents the research carried out at the archaeological site of A Cidadela (Sobrado dos Monxes, A Coruña) in the framework of the Marie Curie Early Medieval Churches: History, Archaeology and Heritage (EMCHAHE) project. This site, excavated through several campaigns since 1934 comprises the remains of a Roman Camp of the 2nd-3rd centuries $\mathrm{AD}$ as well as a series of further late antique and early medieval reoccupations. The study is based on an interdisciplinary approach that combines a review, for the first time, of all the excavations at the site with the stratigraphical analyisis of the standing walls. Special emphasis has been placed on the late antique phases and, mainly, on some structures interpreted as a possible church. Although these are preliminary results, the data already available indicates a more intense reoccupation of the whole site in this period than traditionally considered. Basing on these results, a global assessment of the role of this site in the context of Late Antique Galicia is presented in the final section.
\end{abstract}

Keywords: Roman fort, Early Middle Ages, Late Antique Galicia, Interdisciplinarity, Stratigrapich Reading of Walls, Medieval Archaeology

Received: 10 November, 2014; Accepted: 18 May, 2015

\section{INTRODUCCIÓN ${ }^{1}$}

El yacimiento arqueológico de $A$ Cidadela se sitúa sobre un altozano (480 $\mathrm{msnm})$ que delimitan los ríos Cabalar y Pequeno, dentro de los límites de la parroquia de Santa María de Ciadella, que a su vez pertenece al municipio corunés de Sobrado dos Monxes (Fig. 1). El lugar llamó la atención de los eruditos de inicios del siglo XX y fue excavado en la década de 1930 (COSTA GARCía 2014); pero no será hasta 1981, y bajo la dirección de J. M. Caa- maño, cuando comiencen los trabajos arqueológicos sistemáticos (CAAMAÑO GESTO1984, 1987). En 1987, tras haber calibrado el enorme potencial del yacimiento, la Xunta de Galicia decidió adquirir los terrenos que lo albergan, favoreciendo la continuidad de las intervenciones durante las décadas de 1990 y 2000 (CAAMAÑO GESTO \& FERNÁNDEZ RODRÍGUEZ 2002; RAMIL GONZÁLEZ et al. 2013).

Hasta la fecha, la investigación se ha centrado

\footnotetext{
(1) Investigadora Contratada, Instituto de Investigacións Tecnolóxicas, Laboratorio de Patrimonio, Paleoambiente e Paisaxe, Instituto de Investigacións Tecnolóxicas, Universidade de Santiago de Compostela, Ed. Monte da Condesa, USC, Campus Sur, 15782 Santiago de Compostela. Email: rebenoloxicas, Universida ca.blanco.rotea@usc.es

${ }^{(2)}$ Doctor en Arqueología, Departamento de Historia I, Universidade de Santiago de Compostela. Email: icscipio@gmail.com

${ }^{(3)}$ Investigador postdoctoral contratado Ramón y Cajal / Marie Curie CIG, Departamento de Historia I, Universidade de Santiago de Compostela. Email: josecarlos.sanchez@usc.es

${ }^{1}$ Este trabajo forma parte del proyecto Early Medieval Churches: History, Archaeology and Heritage (EMCHAHE), financiado por una ayuda europea Marie Curie Career Integration Grant (Grant agreement - PCIG12-GA-2012-334068) de la Agencia Europea de Investigación (Frame Program 7), con una duración de 4 años (2013-2017) y desarrollado en la Universidade de Santiago de Compostela bajo la dirección de José Carlos Sánchez-Pardo.
} 


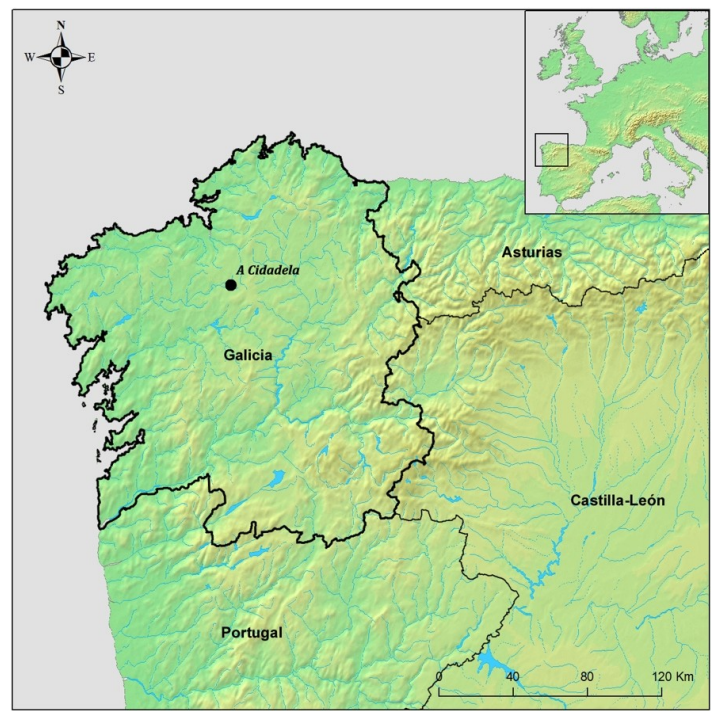

Fig. 1. Mapa de Galicia, su relación con Europa y localización del yacimiento de A Cidadela.

Fig. 1. Map showing the location of Galicia and the site of A Cidadela.

fundamentalmente en la definición y caracterización formal de la primera fase de ocupación del yacimiento, que corresponde a un asentamiento romano de marcada naturaleza militar. Una primera adscripción cronológica de este horizonte (siglos II-IV d. C.), la definición de los límites estrictos del recinto fortifica$\mathrm{do}^{2}$ o la identificación de la cohors I Celtiberorum como unidad ocupante del mismo (CAAMAÑO GESTO 1984, 1989b) fueron los principales logros de los primeros años de excavación. Posteriores campañas tuvieron como objetivo el estudio detallado de las defensas del fuerte en el sector occidental ${ }^{3}$ o la excavación sistemática de las edificaciones que integran los latera praetorii ${ }^{4}$, siendo puntuales las intervenciones fuera de estas áreas. En el momento de concluirse la última intervención en 2010 (RAMIL GONZÁLEZ et al. 2013), de los aproximadamente $28.880 \mathrm{~m}^{2}$ de superficie que ocupa el fuerte - defensas incluidas habían sido excavados unos $4.440 \mathrm{~m}^{2}$, lo que supone menos del $15,4 \%$ del total.

Desde las primeras excavaciones se venía documentando una serie de evidencias que manifestaban la ocupación del lugar con posterioridad al abandono del fuerte romano. Pese a la entidad de las estructuras y los materiales descubiertos, en ningún momento se acometió un estudio integral de las distintas fases posromanas, que fueron agrupadas en un horizonte unitario. En las correspondientes memorias de excavación éste pasó a ser defini- do vagamente como "germánico" o "postcampamental" y se dató en el siglo VII d. C. en base al hallazgo de varias piezas metálicas (Fig. 14) y sus paralelos peninsulares (CAAMAÑO GESTO 1983; 1991; RAMIL GONZÁLEZ 2007). Sólo muy recientemente se ha reivindicado la importancia de estos restos para la comprensión del paisaje interior galaico en época posromana, identificándose e individualizándose por vez primera diversas fases de ocupación durante los períodos tardoantiguo y altomedieval (COSTA GARCÍA \& VARELA GÓMEZ 2011; COSTA GARCÍA et al. 2012: 459-463). Sin embargo, como veremos a continuación, todavía son muchas las cuestiones que quedan por resolver con respecto a estas fases.

Vinculada a una de estas fases se documentó una estructura de planta rectangular y ábside orientado al este que fue identificada como posible iglesia y se dató en el siglo VII (COSTA García \& VARELA GÓMEZ 2011: 185). Este hecho contribuyó a su inclusión como caso de estudio en el proyecto Early Medieval Churches: History, Archaeology and Heritage (EMCHAHE), que pretende ahondar en el estudio histórico-arqueológico de las iglesias tardoantiguas y altomedievales en Galicia (SÁNCHEZ PARDO \& BLANCO-ROTEA 2014). La finalidad del presente trabajo es exponer los primeros resultados de la aplicación de una metodología específica para la revisión y análisis del yacimiento en su conjunto que se centra en la comprensión de su dimensión constructiva, prestando especial atención al período posromano.

\section{METODOLOGÍA DE TRABAJO}

Para el estudio de las fases posromanas del yacimiento debíamos establecer una estrategia que nos permitiera identificar con exactitud qué elementos de la arquitectura castrametacional correspondían a estos períodos, cuáles eran sus características y en qué estado se conservaban. Pero a la vez, dicha estrategia debía adaptarse y afrontar una serie de problemas y limitaciones de la investigación precedente sobre este yacimiento. Los trabajos realizados hasta la fecha, a pesar del importante avance que supusieron para el conocimiento del fuerte, contaban con una deficiente documentación estratigráfica que, además, no había sido cotejada entre las diferentes intervenciones desarrolladas a lo largo de los años. La cronología del yacimiento se estableció, fundamentalmente, en base al estudio de los materiales (CAAMAÑo GeSto 1984, 1990b; CAAMAÑo Gesto et al. 2000; CAAMAÑO GESTO \& FERNÁNDEZ RODRÍGUEZ 2006), pero nunca se ha planteado un estudio

${ }^{2}$ El fuerte de Cidadela adopta con total regularidad la característica planta en forma de naipe de las fortificaciones altoimperiales (COSTA 2013: 209-210; 2014a: 164-165). Con una longitud de aproximadamente $178 \mathrm{~m}$ y una anchura de casi $148 \mathrm{~m}$ (600 x 500 pedes monetales) tendría el recinto un perfecto módulo 6:5 y una superficie total de unas 2,63 ha -fosos excluidos-, dimensiones más que notables para el asentamiento de una unidad auxiliar quingenaria y equitata. ${ }^{3}$ El sistema defensivo estaría formado por un único foso en V - fossa fastigata- y una muralla pétrea de más de tres metros de anchura (CAAMAÑO 1997; CosTA 2013: 210-213). En los esquinales y a tramos regulares en los lienzos se disponía cierto número de torres -de planta trapezoidal las primeras y cuadrangular las segundas-. Completaban el esquema defensivo cuatro puertas monumentales flanquedas a su vez por sendas torres.

${ }^{4}$ Este espacio, situado entre las vías principalis y quintana es donde solían ubicarse algunas de las más importantes edificaciones campamentales (JOHNSON 1983: 35). En el caso de A Cidadela, ocuparían la posición central los principia o cuartel general, mientras que a sus lados se hallan dos complejos edilicios cuya funcionalidad última todavía no ha sido convenientemente aclarada (CAAMAÑo \& FERNÁNDEZ 2002; COSTA 2010; 2013: 213-218). 
pormenorizado de la arquitectura que permitiera recuperar su secuencia constructiva usando metodologías adecuadas como es la lectura estratigráfica de paramentos. Por último, las propuestas sobre las fases constructivas realizadas hasta el momento (COSTA GARCía 2010; COSTA GARCÍA \& VARELA GÓMEZ 2011) se han basado en un estudio eminentemente formal y tipológico -sobre todo para el caso de la planta de la estructura identificada como iglesia- pero no en un análisis estratigráfico sistemático ${ }^{5}$.

En base a todo esto, hemos diseñado una estrategia específica para la completa revisión y análisis de las estratigrafías y fases de este yacimiento. Dicha estrategia se basa en trabajos anteriores que realizamos en yacimientos de características similares: habían sido excavados con anterioridad, con metodologías en muchas ocasiones preestratigráficas; en ellos no se había hecho una lectura detallada de los paramentos; y se encontraban en un importante estado de abandono que había deteriorado los muros en altura, por lo que era preciso observar en detalle las relaciones entre unidades estratigráficas (en adelante UE) tanto en vertical como en horizontal. Nos referimos i.e. al estudio de los castros de Elviña, Borneiro o Vigo (MAÑANA-BORRAZÁs et al. 2002: 68 -79; CRIADO BOAdO \& GONZÁlEZ MÉNDEZ 2003:
33-35; BLANCO-ROTEA 2007; BLANCO-ROTEA \& MAÑANA-BorRAZÁs 2010; GONZÁLEZ MÉNDEZ \& BLANCO-ROTEA 2011).

Concretamente, la metodología elaborada para el yacimiento de $A$ Cidadela consta de cinco fases:

1. Lectura de paramentos de dos grandes sectores del yacimiento (Fig. 2) seleccionados por su potencia estratigráfica, la abundancia y calidad de la información derivada de su reciente excavación, la posible existencia de la iglesia comentada o la presencia de tumbas. Se aplicó, como es habitual, el método Harris adaptado al estudio de las construcciones históricas (PARENTI 1995; CABALLERO ZOREDA 1995, 1996). Se optó en concreto por una lectura de registro rápido consistente en la diferenciación de todas las UE documentadas (Fig. 3 y 5), empleándose en su denominación las siglas UEM -Unidad Estratigráfica Muraria- a fin de evitar confusiones con la relación de UE usada en las excavaciones. Paso seguido, se procedió a su descripción básica en las fichas de registro rápido (Tabla 1) y a su delimitación sobre la planimetría. Finalmente, se ordenaron las UEM en los diagramas estratigráficos de cada sector (Figs. 4 y 6).
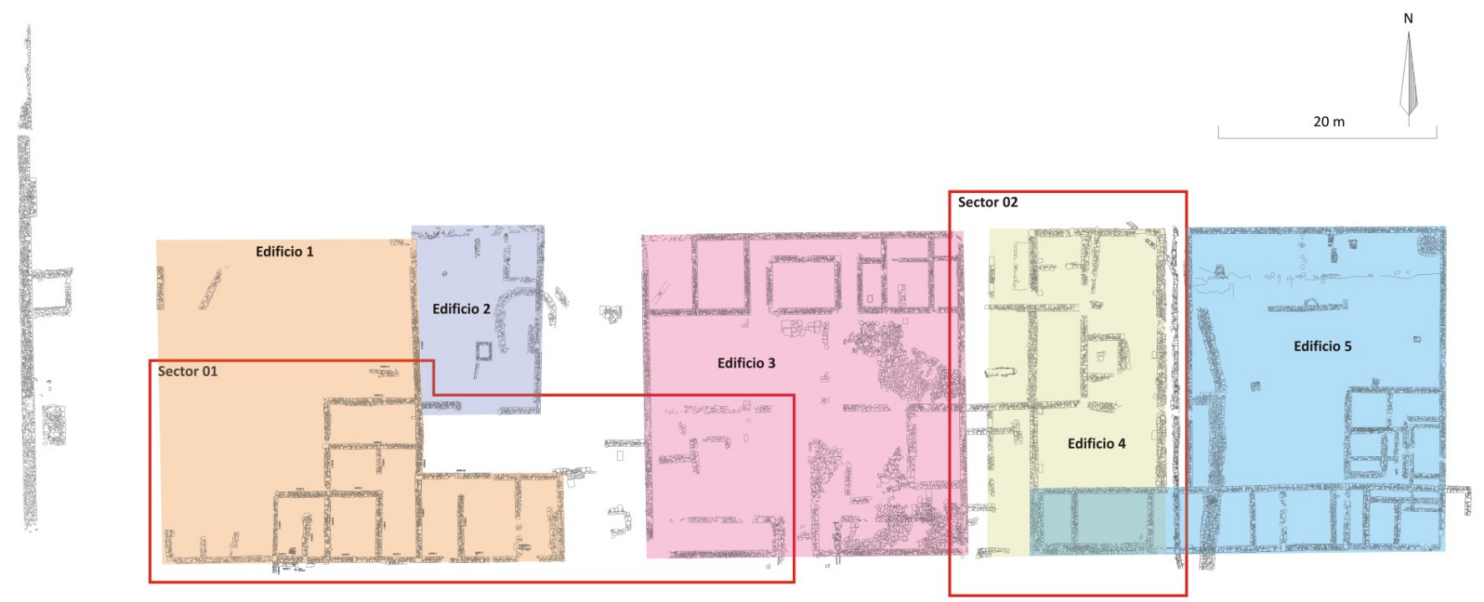

Fig. 2. Sectores 01 y 02 en los que se ha llevado a cabo la lectura estratigráfica de paramentos. En colores se han marcado los distintos edificios identificados en el área excavada del recinto militar. La planimetría que empleamos se realizó en el contexto del proyecto Conservación, escavación arqueolóxica do campamento romano de Cidadela, en Sobrado dos Monxes (2009-CP175), del que es investigador principal: José Manuel Caamaño Gesto (Contrato con entidades públicas, Consellería de Cultura e Turismo; Fecha: 28/08/2009 - 15/1/2010).

Fig. 2. Sectors 01 and 02 in which stratrigraphic analysis of walls have been carried out. Each identified building has been coloured. Plan made in the project Conservación, escavación arqueolóxica do campamento romano de Cidadela, en Sobrado dos Monxes (2009-CP175), directed by José Manuel Caamaño Gesto (Contract with public bodies, Consellería de Cultura e Turismo; Fecha: 28/08/2009 - 15/1 /2010). 


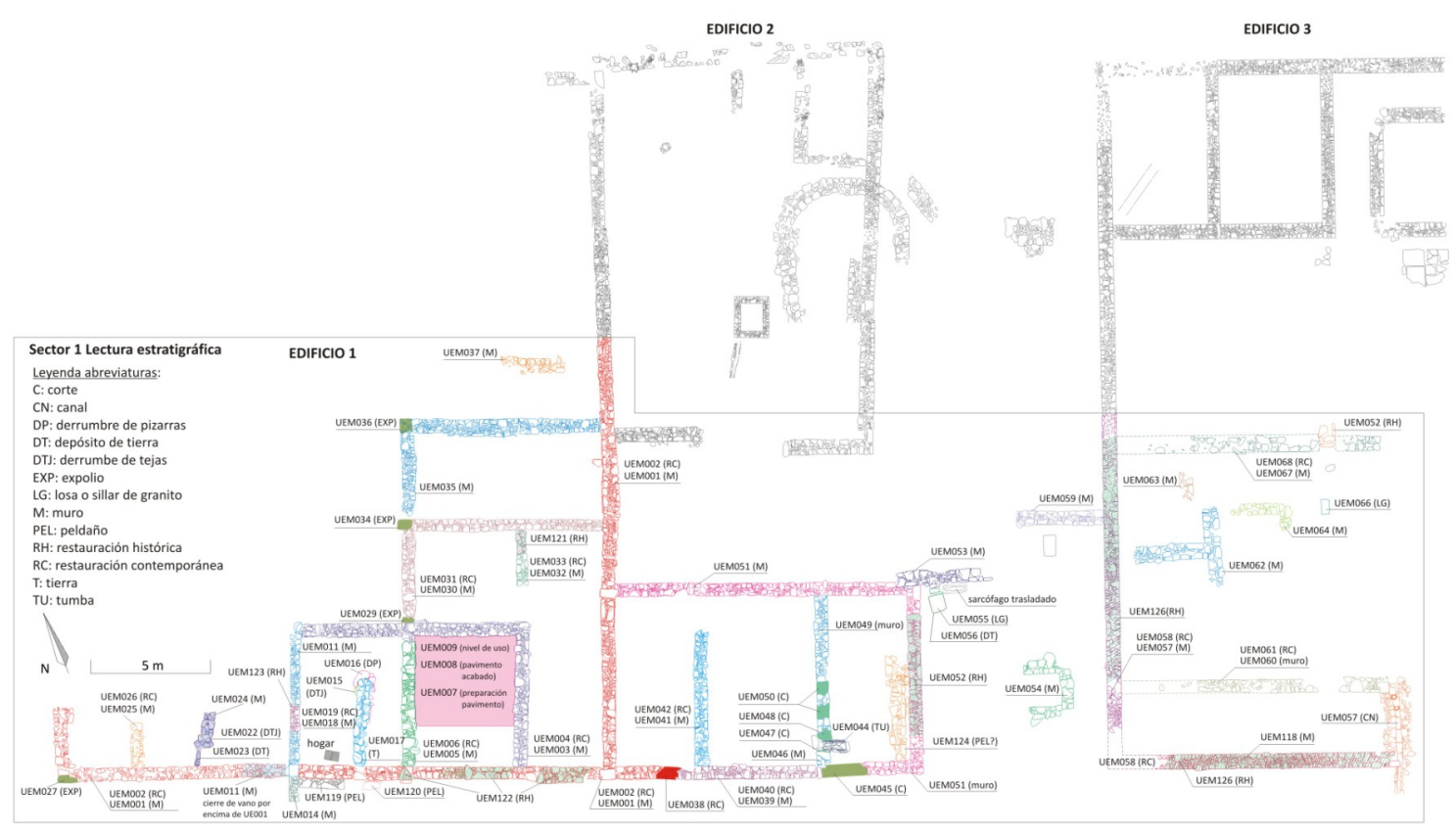

Fig. 3. Diferenciación de UEM en el Sector 01.

Fig. 3. Wall stratigraphic units identified in sector 01 .

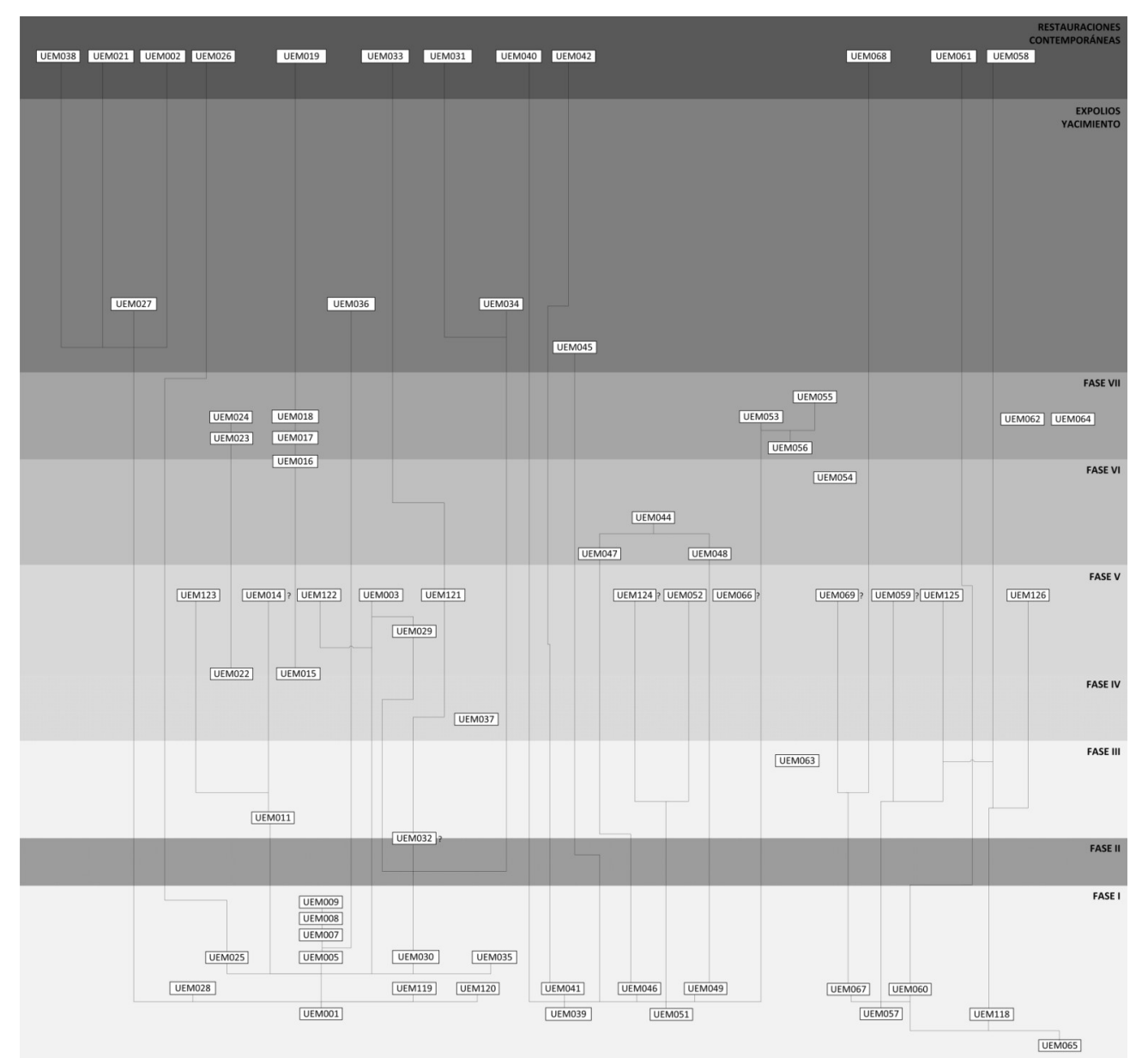

Fig. 4. Diagrama estratigráfico del Sector 01.

Fig. 4. Stratigraphic diagram of Sector 01. 
Análisis de la evolución constructiva de las estructuras excavadas en el yacimiento de A Cidadela (Sobrado dos Monxes, A Coruña) y propuestas interpretativas sobre sus "fases tardoantiguas"

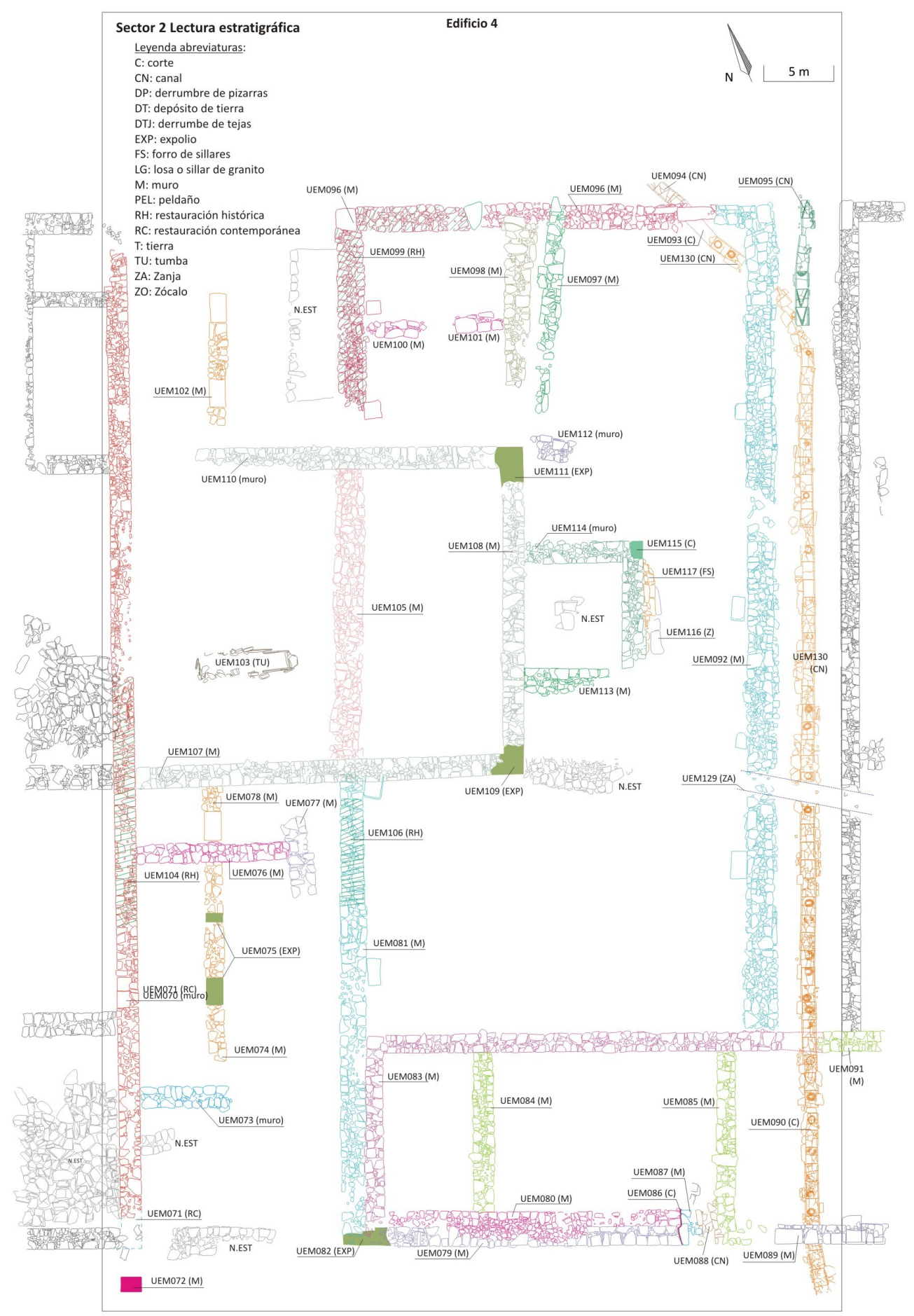

Fig. 5. Diferenciación de UEM en el Sector 02.

Fig. 5. Wall stratigraphic units identified in sector 02 . 


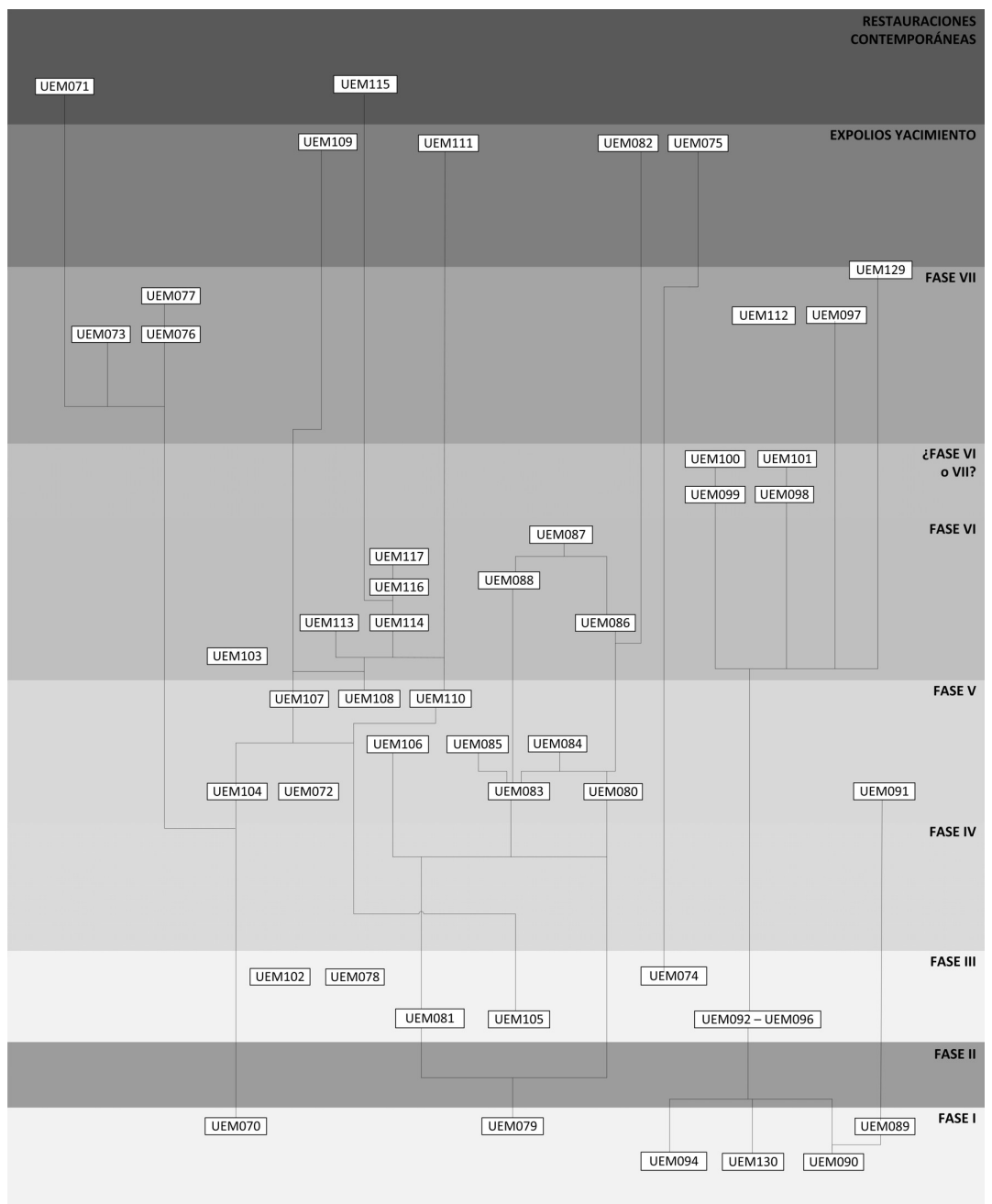

Fig. 6. Diagrama estratigráfico del sector 02 .

Fig. 6. Stratigraphic diagram of Sector 02

Tabla 1. Listado de UEM (Unidades Estratigráficas Murarias) diferenciadas mediante la lectura estratigráfica de paramentos. Table 1. List of UEM (Wall stratigraphic units) obtained through the stratigraphic analysis of the two studied sectors in the site.

\begin{tabular}{|l|l|l|l|l|}
\hline $\mathbf{N}^{\mathbf{0}}$ & Sect & Descripción breve & Observaciones & Fase \\
\hline UEM001 & 1 & Muro que forma la fachada sur del Edificio 1. Dirección E-O. & I \\
\hline UEM002 & 1 & Restauración contemporánea del coronamiento del muro UEM001. & Contemp. \\
\hline UEM003 & 1 & Muro perpendicular al muro UEM001, tiene una planta en L. & V \\
\hline UEM004 & 1 & Restauración contemporánea del coronamiento del muro UEM003. & Contemp. \\
\hline UEM005 & 1 & Muro perpendicular a los muros UEM001 y UEM003, se sitúa entre ambos. & I \\
\hline UEM006 & 1 & Restauración contemporánea del coronamiento del muro UEM005. & Contemp. \\
\hline UEM007 & 1 & $\begin{array}{l}\text { Base de piedras del pavimento de estancia formada por los muros UEM001, } \\
\text { UEM003 y UEM005 }\end{array}$ & I \\
\hline UEM008 & 1 & Depósito de grava y teja machacada situado por encima de la UEM007. & I \\
\hline UEM009 & 1 & Nivel de uso del pavimento formado pos las UEM007 y UEM008. & I \\
\hline UEM010 & 1 & Corte en el extremo oeste del muro UEM003, para adosar muro UEM011 & ELIMINADA & \\
\hline UEM011 & 1 & $\begin{array}{l}\text { Muro perpendicular al muro UEM001. Cierra el espacio formado por este y los } \\
\text { muros UEM005 y UEM003 }\end{array}$ & III \\
\hline UEM012 & 1 & $\begin{array}{l}\text { Corte practicado en extremo oeste del muro UEM001, para construir muro } \\
\text { UEM011. }\end{array}$ & ELIMINADA & \\
\hline UEM013 & 1 & $\begin{array}{l}\text { Corte practicado en extremo este del muro UEM020, para construir el muro } \\
\text { UEM011. }\end{array}$ & ELIMINADA & \\
\hline UEM014 & 1 & $\begin{array}{l}\text { Posible muro que sigue la orientación del muro UEM011, pero hacia el exterior } \\
\text { del Edificio 1. }\end{array}$ & V? \\
\hline
\end{tabular}


Análisis de la evolución constructiva de las estructuras excavadas en el yacimiento de A Cidadela (Sobrado dos Monxes, A Coruña) y propuestas interpretativas sobre sus "fases tardoantiguas"

\begin{tabular}{|c|c|c|c|c|}
\hline UEM015 & 1 & Derrumbe de teja situado por debajo de la UEM016 & & IV? / V? \\
\hline UEM016 & 1 & $\begin{array}{l}\text { Derrumbe de lajas de pizarra agujereadas situado por encima de la UEM016 y } \\
\text { por debajo de la UEM017. }\end{array}$ & & VI? / VII? \\
\hline UEM017 & 1 & $\begin{array}{l}\text { Depósito de tierra, piedra, fragmentos de teja y de lajas de pizarra, sobre de- } \\
\text { rrumbe UE016 y bajo muro UEM018. }\end{array}$ & & VII \\
\hline UEM018 & 1 & $\begin{array}{l}\text { Muro dentro de una estancia (UEM001, UEM003, UEM005 y UEM011), con } \\
\text { distinta orientación a estos. }\end{array}$ & & VII \\
\hline UEM019 & 1 & Restauración contemporánea del coronamiento del muro UEM018. & & Contemp. \\
\hline UEM020 & 1 & $\begin{array}{l}\text { Muro de fachadas sur y oeste del Edificio 1, con dirección E-O. Continúa la } \\
\text { línea del muro UEM001. }\end{array}$ & ELIMINADA & \\
\hline UEM021 & 1 & Restauración contemporánea del coronamiento del muro UEM001. & & Contemp. \\
\hline UEM022 & 1 & $\begin{array}{l}\text { Restos de un derrumbe de piedras y tejas, por debajo de la capa de tierra } \\
\text { UEM023 y del muro UEM024. }\end{array}$ & & IV? / V? \\
\hline UEM023 & 1 & Capa de tierra por debajo del muro UEM024. & & VII \\
\hline UEM024 & 1 & Fragmento de muro situado al norte del muro UE001, en la zona SO del Edificio 1. & & VII \\
\hline UEM025 & 1 & Muro perpendicular al muro UEM001. & & $\mathbf{I}$ \\
\hline UEM026 & 1 & Restauración contemporánea del coronamiento del muro UEM025. & & Contemp. \\
\hline UEM027 & 1 & Corte para expolio de sillar en esquina SO del Edificio 1. & & Expolios \\
\hline UEM028 & 1 & Restos de posible pavimento al exterior de la fachada oeste del Edifício 1. & & I \\
\hline UEM029 & 1 & $\begin{array}{l}\text { Corte en el extremo sur del muro UEM030, posiblemente practicado para } \\
\text { construir el muro UEM003. }\end{array}$ & & $\mathbf{V}$ \\
\hline UEM030 & 1 & Muro de planta en L, que continúa la línea del muro UEM005. & $\begin{array}{l}\text { Podría ser el muro } \\
\text { UEM005. }\end{array}$ & I \\
\hline UEM031 & 1 & Restauración contemporánea del coronamiento del muro UEM030. & & Contemp. \\
\hline UEM032 & 1 & Muro perpendicular al muro UEM030, adosado a éste. & & II? / III? \\
\hline UEM033 & 1 & Restauración contemporánea del coronamiento del muro UEM032. & & Contemp. \\
\hline UEM034 & 1 & $\begin{array}{l}\text { Corte practicado en el esquinal NO del muro UEM030, posiblemente para } \\
\text { expolio de un sillar. }\end{array}$ & & Expolios \\
\hline UEM035 & 1 & Muro de planta en L situado al norte del muro UEM030. & & I \\
\hline UEM036 & 1 & $\begin{array}{l}\text { Corte practicado en el esquinal NO del muro UEM005, posiblemente para } \\
\text { expolio de un sillar. }\end{array}$ & & Expolios \\
\hline UEM037 & 1 & $\begin{array}{l}\text { Restos de un muro, situado al norte del muro UEM035. Muy arrasado. Está } \\
\text { sobre un pavimento anterior. }\end{array}$ & & IV \\
\hline UEM038 & 1 & Restauración contemporánea entre los muros UEM001 y UEM039. & & Contemp. \\
\hline UEM039 & 1 & $\begin{array}{l}\text { Muro de la fachadas sur del Edificio 3. Dirección E-O. Continúa la línea del } \\
\text { muro UEM001 }\end{array}$ & $\begin{array}{l}\text { Podría ser el muro } \\
\text { UEM001. }\end{array}$ & I \\
\hline UEM040 & 1 & Restauración contemporánea del coronamiento del muro UEM039. & & Contemp. \\
\hline UEM041 & 1 & Muro perpendicular al muro UE039, con una orientación N-S. & & I \\
\hline UEM042 & 1 & Restauración contemporánea del coronamiento del muro UEM041. & Restauración 2007. & Contemp. \\
\hline UEM043 & 1 & Corte en el extremo $\mathrm{N}$ del muro UEM041. & & \\
\hline UEM044 & 1 & Tumba de lajas con cabecera de granito, con orientación O-E. & & VI \\
\hline UEM045 & 1 & Corte entre el muro UEM039 y el muro UEM051. & & Expolios \\
\hline UEM046 & 1 & Muro perpendicular al muro UEM039. & & I \\
\hline UEM047 & 1 & $\begin{array}{l}\text { Corte practicado en el muro UEM046, para disponer la tumba de lajas } \\
\text { UEM044. }\end{array}$ & & VI \\
\hline UEM048 & 1 & $\begin{array}{l}\text { Corte practicado en el muro UEM049, para disponer la tumba de lajas } \\
\text { UEM044. }\end{array}$ & & VI \\
\hline UEM049 & 1 & $\begin{array}{l}\text { Muro que sigue la orientación N-S del muro UEM046, se ¿apoya/adosa/une? } \\
\text { en el muro UEM051 }\end{array}$ & $\begin{array}{l}\text { Podría ser el muro } \\
\text { UEM046. }\end{array}$ & I \\
\hline UEM050 & 1 & Dos cortes practicados en el muro UE049, posiblemente para expolio de material. & & Expolios \\
\hline UEM051 & 1 & $\begin{array}{l}\text { Muro con una planta en L, que en su lado sur constituye la fachada sur del } \\
\text { Edificio 3, y que gira hacia el norte }\end{array}$ & & I \\
\hline UEM052 & 1 & $\begin{array}{l}\text { Reconstrucción de la parte alta del muro UEM052 en época histórica. Se em- } \\
\text { plean granitos y tizones, los cuales no en los muros de las fases más antiguas } \\
\text { del yacimiento. }\end{array}$ & & $\mathbf{V}$ \\
\hline UEM053 & 1 & $\begin{array}{l}\text { Muro que se superpone al lado norte del muro UEM051 y su reconstrucción } \\
\text { UEM052. Con una orientación E-O, ligeramente girada hacia el norte. Reutili- } \\
\text { za una pilastra de granito con moldura. }\end{array}$ & & VII \\
\hline UEM054 & 1 & $\begin{array}{l}\text { Estructura de planta en U, abierta por el oeste, formada por un muro de mam- } \\
\text { postería irregular. Se sitúa al este del muro UEM051-052 }\end{array}$ & $\begin{array}{l}\text { Se relaciona formal- } \\
\text { mente con la estruc- } \\
\text { tura absidial de } \\
\text { posible iglesia. }\end{array}$ & VI \\
\hline UEM055 & 1 & Sillar de granito situado al sur del muro UEM053. Muy bien trabajado. & $\begin{array}{l}\text { Podría ser reutili- } \\
\text { zación pieza Fase } \\
\text { I. }\end{array}$ & VII \\
\hline
\end{tabular}




\begin{tabular}{|c|c|c|c|c|}
\hline UEM056 & 1 & Depósito de tierra localizado por debajo de la UEM055. & & VII \\
\hline UEM057 & 1 & Muro que conforma la fachada oeste del Edificio 3. & & I \\
\hline UEM058 & 1 & $\begin{array}{l}\text { Restauración contemporánea del coronamiento de los muros UEM057 y } \\
\text { UEM118 y la unión entre estos. }\end{array}$ & & Contemp. \\
\hline UEM059 & 1 & $\begin{array}{l}\text { Muro adosado por el oeste al muro UEM057, perpendicular a éste. Tiene una } \\
\text { orientación E-O. }\end{array}$ & & V? \\
\hline UEM060 & 1 & Muro muy arrasado perpendicular al muro UEM118. Imbrica con el muro UEM057. & & I \\
\hline UEM061 & 1 & Restauración contemporánea del coronamiento del muro UEM060. & & Contemp. \\
\hline UEM062 & 1 & Muro con una planta en T, situado al este del muro UEM057. & & VII \\
\hline UEM063 & 1 & Restos de un muro, muy arrasado, situado al norte del muro UEM062. & & III \\
\hline UEM064 & 1 & $\begin{array}{l}\text { Restos de un muro, de planta en L, muy arrasado, situado al NE del muro } \\
\text { UEM062. }\end{array}$ & & VII \\
\hline UEM065 & 1 & Canalización (casi no se aprecia), situada entre los muros UEM060 y UME1 18. & & I \\
\hline UEM066 & 1 & Sillar de granito situado al este del muro UEM064. & & $\mathrm{V}$ ? \\
\hline UEM067 & 1 & Muro muy arrasado, con una orientación O-E, perpendicular al muro UEM057. & & I \\
\hline UEM068 & 1 & Restauración contemporánea del coronamiento del muro UEM067. & & Contemp. \\
\hline UEM069 & 1 & Muro ¿adosado/unido? al muro UEM067, dispuesto en sentido perpendicular a éste. & & $\mathbf{V}$ ? \\
\hline UEM070 & 2 & Muro que constituye la fachada este del Edificio 3. & & I \\
\hline UEM071 & 2 & $\begin{array}{l}\text { Restauración contemporánea del coronamiento del muro UEM070 y de su } \\
\text { esquinal NE. }\end{array}$ & & Contemp. \\
\hline UEM072 & 2 & $\begin{array}{l}\text { Posible muro (se mete debajo del perfil de la excavación). Sigue la orientación } \\
\text { del muro UEM070. }\end{array}$ & & $\mathbf{v}$ \\
\hline UEM073 & 2 & Muro adosado por el exterior al muro UEM070, con una orientación O-E. & & VII \\
\hline UEM074 & 2 & $\begin{array}{l}\text { Muro con una orientación N-S, dispuesto de forma paralela al muro UEM070. } \\
\text { Presenta algunas roturas, con una alternancia más o menos regular que podrían } \\
\text { corresponder al expolio e sillares. }\end{array}$ & & III \\
\hline UEM075 & 2 & Roturas en el muro UEM074, tal vez para robo de sillares. & & Expolios \\
\hline UEM076 & 2 & $\begin{array}{l}\text { Muro con planta en T, el lado largo se adosa al muro UEM070 por el exterior. } \\
\text { Se apoya sobre un derrumbe UEM077. }\end{array}$ & & VII \\
\hline UEM077 & 2 & Derrumbe sobre el que se apoya el muro UEM076. & & VII \\
\hline UEM078 & 2 & $\begin{array}{l}\text { Muro compuesto por un sillar de granito de } 80 \mathrm{~cm} \text { de largo x } 47 \mathrm{~cm} \text { de ancho y el } \\
\text { resto de mampostería. La parte de mampostería se aprecia mal por estar cubierta de } \\
\text { vegetación. }\end{array}$ & $\begin{array}{l}\text { Podría ser el mismo } \\
\text { muro que el UEM074 } \\
\text { yelUEM102. }\end{array}$ & III \\
\hline UEM079 & 2 & $\begin{array}{l}\text { Muro que conforma la fachada sur de un posible horrea por el exterior. Tiene } \\
\text { una orientación E-O. }\end{array}$ & & I \\
\hline UEM080 & 2 & $\begin{array}{l}\text { Muro paralelo al muro UEM079, adosado a éste por el interior. Tiene una } \\
\text { orientación E-O. }\end{array}$ & & $\mathbf{v}$ \\
\hline UEM081 & 2 & $\begin{array}{l}\text { Muro con una orientación N-S. Posiblemente sea el mismo muro que la UE079, pero el } \\
\text { esquinal entre ambos muros no se aprecia ya que se ha producido un expolio del sillar en } \\
\text { esquina. Se rompe por la construcción del alzado sur de una posible iglesia. Presenta } \\
\text { sillares adosados por su cara interna de forma alternativa, al igual que el muro UE092. }\end{array}$ & $\begin{array}{l}\text { Podría ser el mismo } \\
\text { muro que las } \\
\text { UEM096 y } \\
\text { UEM105. }\end{array}$ & III \\
\hline UEM082 & 2 & Expolio de sillar en esquina entre los muros UEM079 y UEM081. & & Expolios \\
\hline UEM083 & 2 & $\begin{array}{l}\text { Muro perimetral de estructura adosada por el interior al espacio formado por } \\
\text { muros UEM079, UEM081 y UEM092. }\end{array}$ & $\begin{array}{l}\text { Podría ser el mismo } \\
\text { que la UEM080. }\end{array}$ & $\mathbf{v}$ \\
\hline UEM084 & 2 & $\begin{array}{l}\text { Muro que une en sentido N-S los muros UEM079 y UEM083, al oeste del } \\
\text { espacio que conforman ambos. }\end{array}$ & & $\mathbf{v}$ \\
\hline UEM085 & 2 & $\begin{array}{l}\text { Muro que une en sentido N-S los muros UEM079 y UEM083, al este del } \\
\text { espacio que conforman ambos. En el extremo sur dobla hacia el este (esta parte } \\
\text { está muy arrasada). }\end{array}$ & & $\mathbf{v}$ \\
\hline UEM086 & 2 & Corte en el extremo sur de los muros UEM079 y UEM080. & & VI \\
\hline UEM087 & 2 & $\begin{array}{l}\text { Reforma en el corte UE086, practicado en los muros UEM079 y UEM080, para } \\
\text { unificar su anchura. }\end{array}$ & & VI \\
\hline UEM088 & 2 & $\begin{array}{l}\text { Canal/desagüe situado en la zona conformada por los muros UEM086/087 y el } \\
\text { esquinal SO de la UEM085. }\end{array}$ & & VI \\
\hline UEM089 & 2 & Muro dispuesto en sentido E-O que continúa la línea del muro UEM079. & & I \\
\hline UEM090 & 2 & $\begin{array}{l}\text { Canal con base y cubierta de tégula (la mayoría presentan marcas) y piedra en } \\
\text { las paredes laterales, dispuesto en sentido N-S en el lado oeste del edificio 3, al } \\
\text { oeste del mismo por el exterior. }\end{array}$ & & I \\
\hline UEM091 & 2 & $\begin{array}{l}\text { Muro dispuesto en sentido este-oeste, que se adosa y corta al muro de cierre } \\
\text { oeste del edificio } 3 \text {. }\end{array}$ & & $\mathbf{v}$ \\
\hline UEM092 & 2 & $\begin{array}{l}\text { Muro dispuesto en sentido N-S, en paralelo al muro UEM081. Presenta sillares } \\
\text { adosados por el interior a la base del muro, dispuestos regularmente. }\end{array}$ & $\begin{array}{l}\text { El muro presenta } \\
\text { características simila- } \\
\text { res al muro UEM081. }\end{array}$ & III \\
\hline UEM093 & 2 & Corte en el extremo norte del canal UEM090 para construir el muro UEM092. & & III \\
\hline UEM094 & 2 & $\begin{array}{l}\text { Canal. Es la continuación del canal UEM090 por el exterior del muro } \\
\text { UEM092, en su extremo NO. }\end{array}$ & & I \\
\hline
\end{tabular}


Análisis de la evolución constructiva de las estructuras excavadas en el yacimiento de A Cidadela (Sobrado dos Monxes, A Coruña) y propuestas interpretativas sobre sus "fases tardoantiguas"

\begin{tabular}{|c|c|c|c|c|}
\hline UEM095 & 2 & Reforma del canal UEM090, para continuarlo con una orientación S-N. & & III \\
\hline UEM096 & 2 & $\begin{array}{l}\text { Muro con una orientación E-O, que continúa la línea del muro UE092 hacia el } \\
\text { oeste, tras la rotura UEM093. }\end{array}$ & & III \\
\hline UEM097 & 2 & $\begin{array}{l}\text { Muro apoyado en tierra que monta sobre el muro UEM096. Tiene una orienta- } \\
\text { ción NNE-SSO. }\end{array}$ & & VII \\
\hline UEM098 & 2 & $\begin{array}{l}\text { Muro que tiene una orientación N-S, que monta sobre la UEM096 y su reforma } \\
\text { UEM099. }\end{array}$ & & VI? / VII? \\
\hline UEM099 & 2 & $\begin{array}{l}\text { Reforma situada sobre la UEM096. En ella se emplean tizones y un sillar de } \\
\text { granito en la esquina NO. }\end{array}$ & & VI? / VII? \\
\hline UEM0100 & 2 & $\begin{array}{l}\text { Muro dispuesto en sentido O-E que cierra, con la UEM101, un espacio situado } \\
\text { entre los muros UEM096 y UEM098. }\end{array}$ & & VI? / VII? \\
\hline UEM0101 & 2 & $\begin{array}{l}\text { Muro dispuesto en sentido E-O que cierra, con la UEM101, un espacio situado } \\
\text { entre los muros UEM096 y UEM098. }\end{array}$ & & VI? / VII? \\
\hline UEM0102 & 2 & $\begin{array}{l}\text { Muro de mampostería que se alterna con sillares de granito de } 2 \frac{1 / 2}{2} \text { pies x } 1 \frac{1}{1} 2 \\
\text { pies, dispuesto en sentido N-S. Sigue la línea de los muros UEM074 y } \\
\text { UEM078. }\end{array}$ & 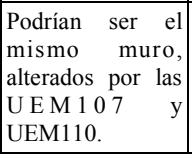 & III \\
\hline UEM0103 & 2 & Tumba de lajas de pizarra y cabecera de granito, orientada en sentido O-E. & & VI \\
\hline UEM0104 & 2 & $\begin{array}{l}\text { Recrecimiento de época histórica, sitiado entre el muro UEM070 y la restaura- } \\
\text { ción contemporánea UEM071. }\end{array}$ & & $\mathbf{V}$ \\
\hline UEM0105 & 2 & $\begin{array}{l}\text { Muro dispuesto en sentido E-O, entre los muros UEM070 y UEM108. Creemos } \\
\text { que constituye el alzado sur de una posible iglesia. }\end{array}$ & & III \\
\hline UEM0106 & 2 & Reconstrucción histórica sobre el muro UEM081. & & $\mathbf{V}$ \\
\hline UEM0107 & 2 & $\begin{array}{l}\text { Muro dispuesto en sentido O-E. Alzado sur de una estancia identificada como } \\
\text { posible iglesia. }\end{array}$ & & $\mathbf{V}$ \\
\hline UEM0108 & 2 & $\begin{array}{l}\text { Muro dispuesto en sentido N-S que une por el extremo este de los muros } \\
\text { UEM108 y UEM110. }\end{array}$ & & $\mathbf{V}$ \\
\hline UEM0109 & 2 & Expolio de la zona situada entre los muros UEM107 y UEM108. & & Expolios \\
\hline UEM0110 & 2 & Muro dispuesto en sentido E-O, situado entre los muros UEM070 y UEM108. & & $\mathbf{V}$ \\
\hline UEM0111 & 2 & Expolio de la zona situada entre los muros UEM108 y UEM110. & & Expolios \\
\hline UEM0112 & 2 & $\begin{array}{l}\text { Muro localizado al este del muro UEM110, enlazado con la rotura UEM111. } \\
\text { No sigue la regularidad del muro UEM110, ligeramente girado hacia el ONO. }\end{array}$ & & VII? \\
\hline UEM0113 & 2 & $\begin{array}{l}\text { Alzado sur de posible ábside. Se emplean granitos. No se observan tizones. } \\
\text { Apoyado sobre depósito de tierra. Zócalo sobresaliente por el interior del paño } \\
\text { del muro. El exterior ha perdido la cara, se observa el relleno del mismo. }\end{array}$ & & VI \\
\hline UEM0114 & 2 & $\begin{array}{l}\text { Muros norte y este de un posible ábside. Han perdido la cara externa, sobre } \\
\text { todo el norte. Están apoyados sobre un depósito de tierra. }\end{array}$ & & VI \\
\hline UEM0115 & 2 & $\begin{array}{l}\text { Rotura en esquinal NE del muro UEM114. Tiene forma rectangular y en el } \\
\text { suelo hay un sillar de iguales dimensiones. }\end{array}$ & $\begin{array}{l}\text { Parece una caída } \\
\text { reciente. }\end{array}$ & Contemp. \\
\hline UEM0116 & 2 & $\begin{array}{l}\text { Zócalo de sillería de granito en cara este del muro UEM114. Sobresale entre } 10 \\
\text { y } 15 \mathrm{~cm} \text { del muro. }\end{array}$ & & VI \\
\hline UEM0117 & 2 & $\begin{array}{l}\text { Forro de sillares de granito y esquisto del muro UEM114. Se apoya sobre el } \\
\text { zócalo UEM116. }\end{array}$ & & VI \\
\hline UEM0118 & 1 & Muro que conforma parte de la fachada sur del Edificio 1. & & I \\
\hline UEM0119 & 1 & Peldaño adosado a la fachada sur del Edificio 1. & & I \\
\hline UEM0120 & 1 & $\begin{array}{l}\text { Sillar situado delante de la fachada sur del Edifico 1, a la misma altura que la } \\
\text { UEM119. }\end{array}$ & & I \\
\hline UEM0121 & 1 & $\begin{array}{l}\text { Reconstrucción con bloques de granito sobre el extremo norte del muro } \\
\text { UEM032. }\end{array}$ & $\begin{array}{l}\text { Similar a los } \\
\text { recrecidos históri- } \\
\text { cos. }\end{array}$ & $\mathbf{V}$ \\
\hline UEM0122 & 1 & Reconstrucción con bloques de granito sobre parte del muro UEM001. & Idem UEM121. & $\mathbf{V}$ \\
\hline UEM0123 & 1 & Reconstrucción con bloques de granito sobre parte del muro UEM011. & Idem UEM121. & $\mathbf{V}$ \\
\hline UEM0124 & 1 & $\begin{array}{l}\text { Muro adosado al muro UEM051 y su reconstrucción UEM052. Posible pelda- } \\
\text { ño. }\end{array}$ & & V? \\
\hline UEM0125 & 1 & Recrecido histórico sobre parte del muro UEM011. & Idem UEM121 & $\mathbf{V}$ \\
\hline UEM0126 & 1 & Recrecido histórico sobre parte del muro UEM118. & Idem UEM121 & $\mathbf{V}$ \\
\hline UEM0127 & 1 & Eliminada UE repetida & & \\
\hline UEM0128 & 2 & Corte entre los muros UEM083 y UEM091, sobre el canal UEM090. & & Contemp.? \\
\hline UEM0129 & 2 & Zanja que corta el canal UEM090 y el muro UEM092. & & VII? / Exp? \\
\hline UEM0130 & 2 & Resto de canal, sería el mismo que el canal UEM090, tras el corte UEM129. & & I \\
\hline
\end{tabular}


2. Revisión y sistematización de los datos pre -estratigráficos y estratigráficos obtenidos de los distintos proyectos de excavación, memorias arqueológicas y publicaciones, de tal manera que pudiéramos reconstruir la secuencia horizontal que los diferentes autores habían registrado en $A$ Cidadela. Esta labor era necesaria ya que no existía un trabajo de síntesis que presentara la estratigrafía global del yacimiento. Por otra parte, dado que éste había sido excavado y consolidado previamente, acudir a estas fuentes de información era fundamental para poder entender o contrastar algunos de los aspectos que documentamos en la lectura estratigráfica ${ }^{6}$. Esta revisión fue extendida a la totalidad del yacimiento, dado que avanzar en la comprensión general del mismo permitiría aproximarnos luego al estudio en detalle de las estructuras.

3. Correlación de los datos procedentes de la lectura estratigráfica vertical y de la estratigrafía horizontal, puesto que su interpretación conjunta resultaba fundamental a la hora de poder comprender, interpretar y datar, de forma relativa, la totalidad de la secuencia.

4. Se completó el análisis estratigráfico con el análisis espacial basado en la descripción formal de los distintos niveles que influyen en la configuración concreta del espacio arquitectónico, tratando con ello de identificar la forma inicial de la que partió ese espacio y los factores organizativos que actúan en él (MAÑANA BORRAZÁs et al. 2002: 33-36); de esta manera, pretendíamos acceder a la forma originaria de los espacios del fuerte romano y observar sus transformaciones en cada fase constructiva, apoyándonos en los resultados de la lectura estratigráfica.

5. Una vez identificada la secuencia se procedió a la extracción de muestras de los morteros y argamasas empleados en los muros de las diferentes fases, sobre todo de las posromanas, con la intención de obtener la datación absoluta por C14 y Luminiscencia Ópticamente Estimulada (OSL) de la secuencia (SANJURJO-SÁNCHEZ et al. 2010; SANJURJO 2012).

\section{EVOLUCIÓN CONSTRUCTIVA Y PERIODIZACIÓN DE LOS SECTORES ESTUDIADOS EN EL YACIMIENTO DE A CIDADELA}

En este apartado presentamos una interpretación conjunta de la evolución constructiva del yacimiento en base a los resultados obtenidos tras la aplicación de la metodología anteriormente descrita (Fig. 7 y 8). Hay que señalar que la cronología que ofrecemos aquí es una hipótesis provisional de trabajo basada en las dataciones propuestas por nuestros predecesores (CAAMAÑO GESTO 1984; 1989; DOVAL GÁlAN 1997; CAAMAÑO GESTO et al. 2000; VÁZQUEZMARTÍNEZ 2005; CAAMAÑO GESTO \& FERNÁNDEZ RODRÍGUEZ 2006; LÓPEZ PÉREZ 2006; Costa García 2009a; 2010), pero en un futuro próximo las dataciones absolutas por OSL de los morteros de varias fases del yacimiento nos permitirán obtener una mayor precisión.

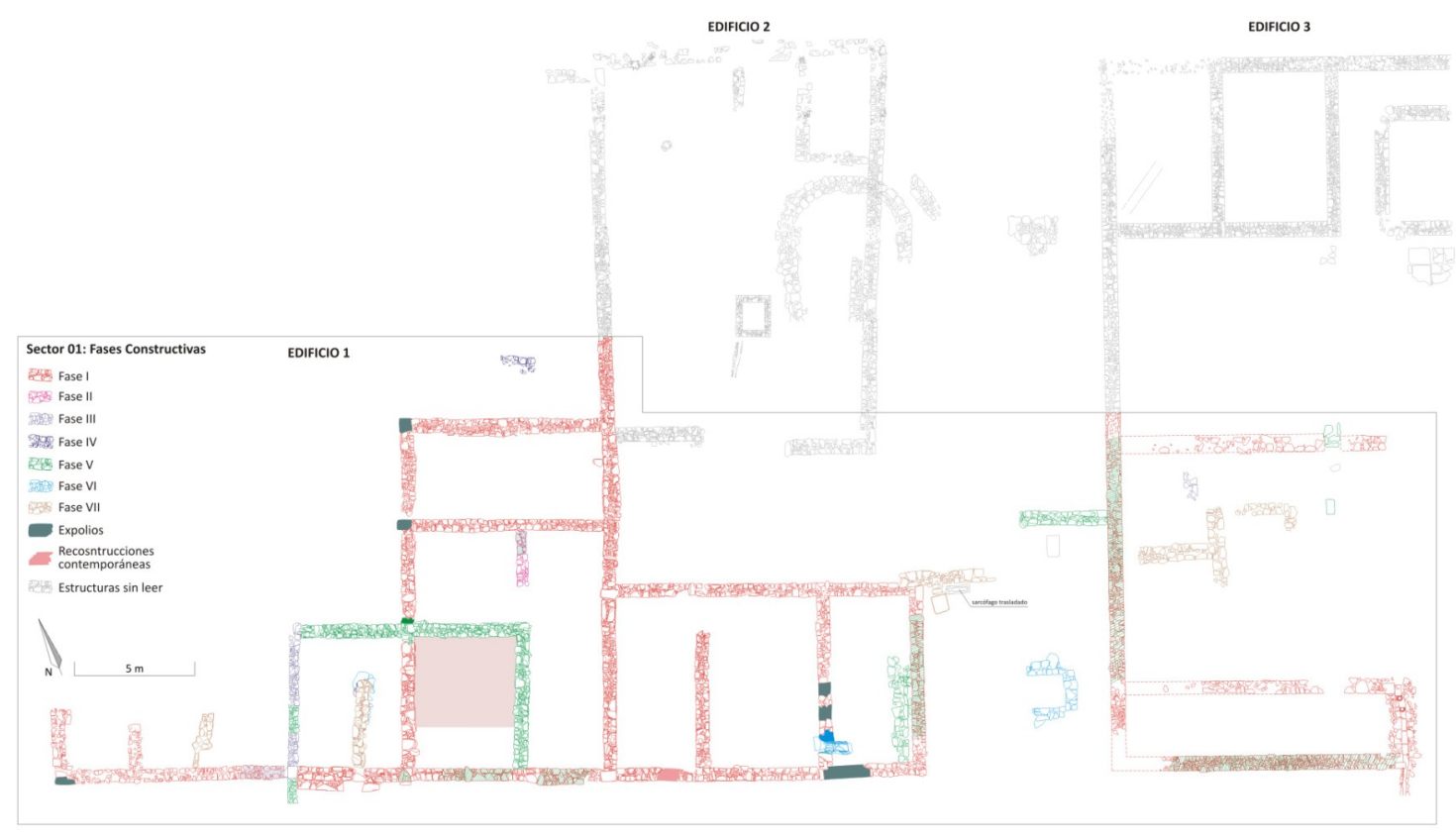

Fig. 7. Planta de fases del Sector 01

Fig. 7. Plan of phases in Sector 01

${ }^{6}$ Muchas de las restauraciones recientes habían ocultado en parte esta estratigrafía, usando, por ejemplo, tizones en zonas restauradas que correspondían a época romana, cuando el aparejo romano carece de ellos. Sí los tienen, sin embargo, el tardoantiguo o el altomedieval, por lo que había que delimitar exactamente el alcance de estas restauraciones. ). 


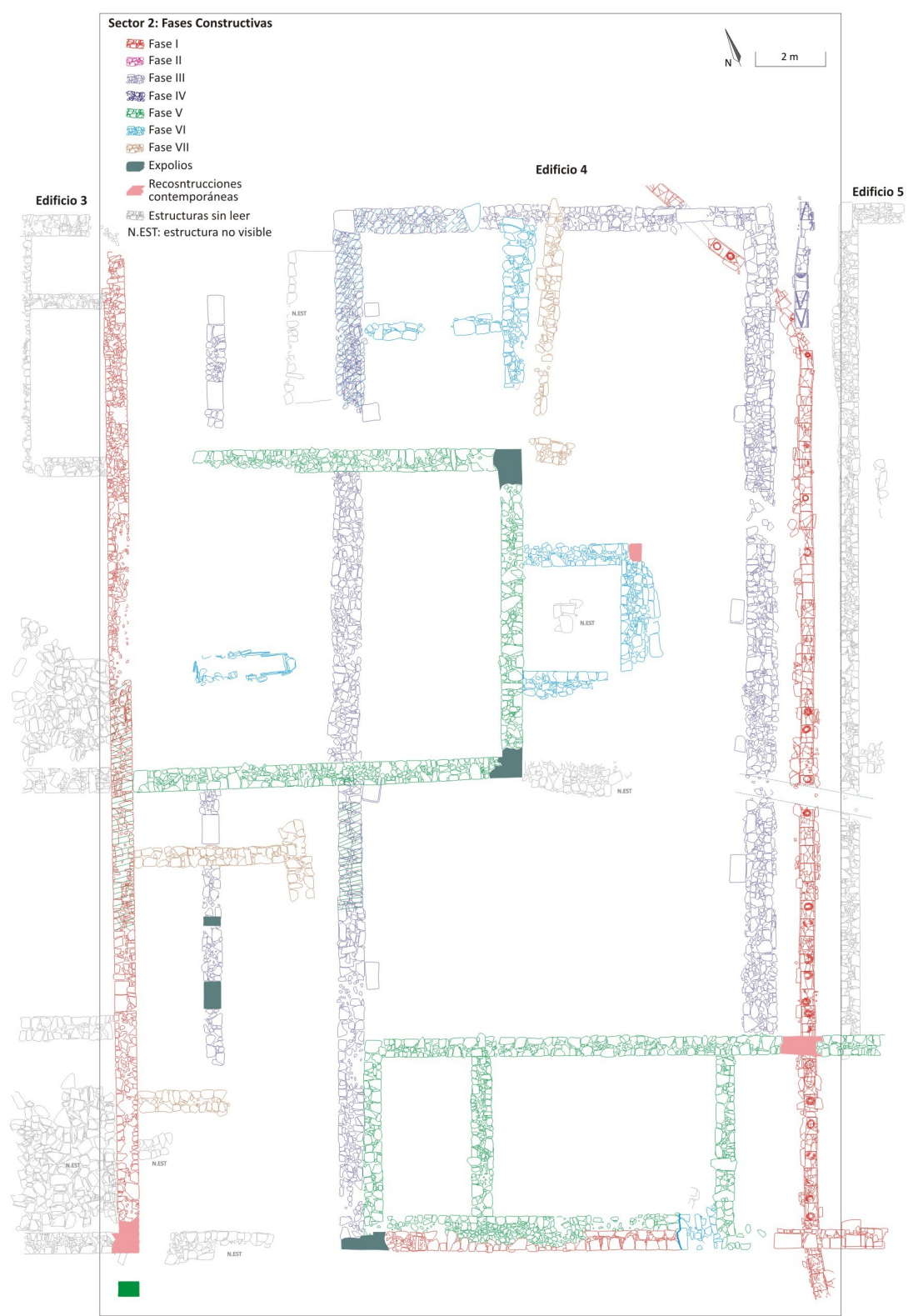

Fig. 8. Planta de fases del Sector 02 .

Fig. 8. Plan of phases in Sector 02.

\subsection{Período romano}

Dentro del período romano se conservan restos de al menos cuatro fases diferentes. La que tiene una mayor presencia en los sectores estudiados es la Fase I, puesto que de la II y la III apenas se conservan estructuras y en algunos casos resulta incluso muy complicada su adscripción a alguno de estos horizontes constructivos.

\subsubsection{Fase 0. Planificación del recinto militar}

Los indicios que se pueden relacionar con esta fase son apenas algunos agujeros de poste bajo el pavimento del interuallum ${ }^{7}$ occidental o frente a la edificación situada en el sector recientemente excava- do al sur de la uia principalis, restos de la presencia de estructuras de carácter perecedero (CAAMAÑO GESTO 1989; RAMIL GONZÁLEZ 2010; COSTA GARCÍA 2013: 222; RAMIL GONZÁLEZ et al. 2013: 273). Probablemente se trate de huellas del andamiaje para la construcción de las edificaciones permanentes ${ }^{8}$, aunque no podemos descartar que algunos sirviesen de apoyo a estructuras de otra funcionalidad: alojamientos provisionales, soporte de cubierta de espacios de producción... Esta fase puede vincularse con la planificación original y primera construcción de la fortificación romana. 


\subsubsection{Fase I. Fundación del asentamiento militar}

Se vinculan a esta fase en el sector 01 las UE: UEM001, UEM005, UEM007, UEM008, UEM009, UEM025, UEM0028, UEM030, UEM035, UEM039, UEM041, UEM046, UEM049, UEM051, UEM057, UEM060, UEM065, UEM067, UEM118, UEM119, UEM120 (Fig. 3). Se corresponden con muros perimetrales y divisiones internas de los edificios 1 y
3, que se organizan respectivamente en torno a un deambulatorio y a un patio de planta rectangular. El Edificio 1 presenta una planta en L y un vano centrado en su fachada sur al que se accede mediante un peldaño desde la uia principalis (Fig. 9). El Edificio 3, que se corresponde con los principia del fuerte, cuenta con una planta cuadrangular $(29,5 \times 29,6 \mathrm{~m})$ con un acceso centrado también desde el sur.
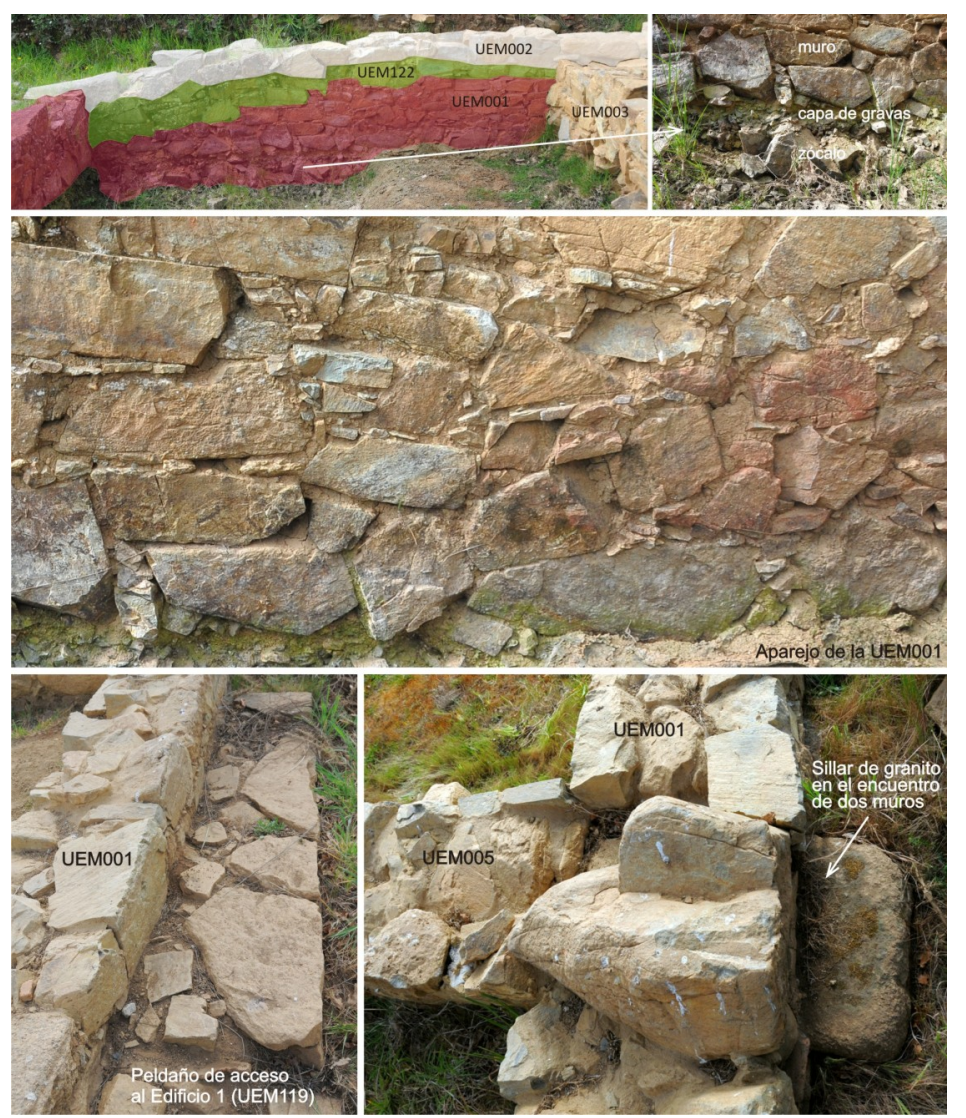

Fig. 9. Diferentes detalles de la UEM001, correspondiente a la fase de fundación del asentamiento militar.

Fig. 9. Details of UEM001, corresponding to the foundation phase of the roman military site

En el sector 02 se identifican las UEM0070, UEM079, UEM089, UEM090, UEM094 y UEM130 (Fig. 5), que se corresponden con las fachadas este del Edificio 3 y sur del Edificio 5. Este último, ubicado al este de los principia, tendría originalmente una planta muy similar y simétrica a la del Edificio 1, en L invertida, pero está muy alterada por las reformas posteriores. Existe además un canal construido con piedra y tejas que discurre paralelo a la fachada oeste del Edificio 5, al final de este se curva hacia el norte.

Esta fase corresponde a la planta castrametacional original, una vez concluida la construcción de los principia y las edificaciones nobles de la fortificación. Guarda una estrecha relación cronológica con la fase anterior adscrita a época trajaneo-adrianea (CAAMAÑO GESTO 1987: 75-76; COSTA GARCÍA 2013 221). En los latera praetorii y zonas aledañas de la uia principalis, los muros siguen un alineamiento norte-sur o este-oeste, la modulación de los espacios es ordenada, reflejo del uso de varias escalas basadas en múltiplos $^{9}$ del pes monetalis ${ }^{10}$ (COSTA GARCIA 2010).

Se emplea un aparejo de mampostería irregular de esquisto -opus incertum-, realizada con materiales de tamaño medio que en algunas zonas tiende a formar pseudo-hiladas, en especial cuando se em- 
plean piezas rectangulares o cuadrangulares. Las juntas tienen ripios, lajas de esquisto y $\operatorname{argamasa}^{11}$. Los muros, que miden entre 51 y $54 \mathrm{~cm}$ de ancho, se componen de dos caras y un nucleus; no se documentan tizones. La primera hilada del muro emplea materiales de mayor tamaño. En la cimentación de los muros de fachada se observa un zócalo sobresaliente sin carear; bajo éste se localiza una capa de gravas para drenaje (Fig. 9). Los muros tabiqueros interiores se encuentran a una cota más elevada que los de fachada (vid. UEM001 in Fig. 9). Se utilizan sillares de granito en los esquinales e intersecciones vistas en fachada y elementos moldurados de granito en las portadas que dan a la uia principalis $^{12}$ (Figs. 9 y 10).

Los pavimentos vinculados a esta fase son en su mayoría de tierra apisonada y se asientan sobre varias capas de drenaje realizadas con grava y piedra (UEM007 y 008). En algunas zonas, como en el esquinal suroeste del Edificio 1 (UEM028), se documenta también opus signinum, aunque parece que se emplea de forma selectiva.
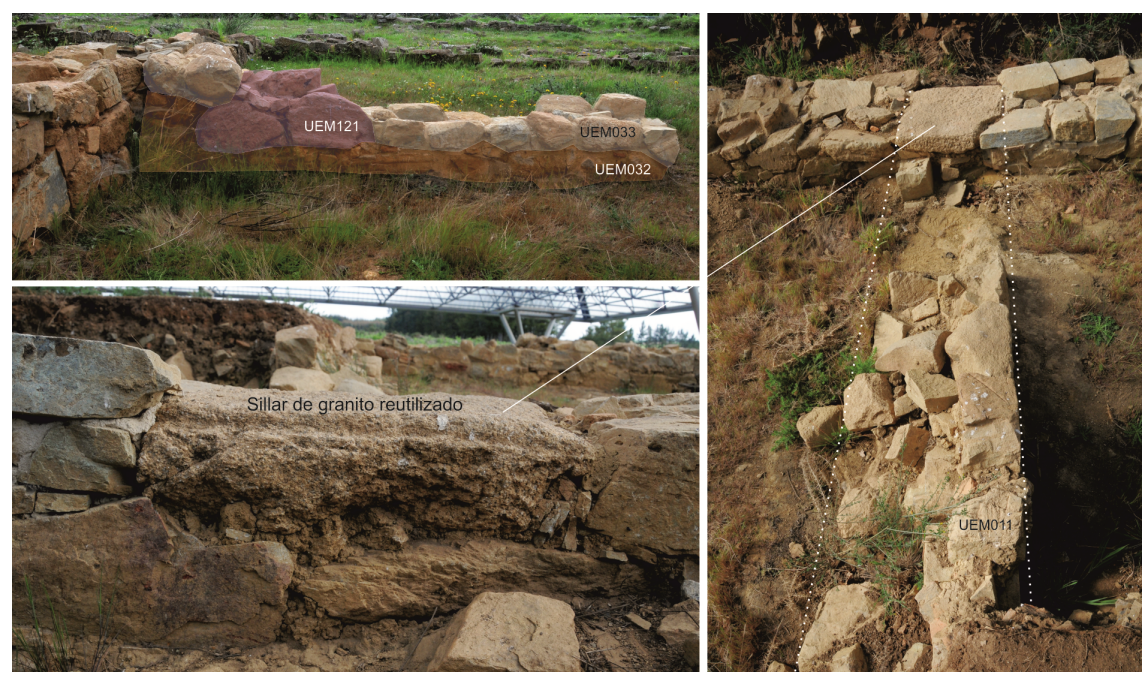

Fig. 10. UEM correspondientes a la Fase II (UEM032) y a la III (UEM011), ambos en el Edificio 1. Fig. 10. UEM of Phases II (UEM032) and III (UEM011), both in building 1.

\subsubsection{Fase II. Ocupación del fuerte romano}

Únicamente pudimos adscribir en el Sector 01 a esta fase la UEM032. Se trata de un muro muy arrasado de unos 45-46 cm de anchura, con una orientación norte-sur que se adosa al muro UEM030 de la Fase I (Fig. 10). Sus dos caras están realizadas en mampostería irregular de esquisto con las juntas rellenas de ripios, fragmentos de teja y argamasa de arcilla. Parece haber servido como divisor interno de una de las estancias del Edificio 1.

Este muro se ha vinculado a la Fase II porque mantiene una misma tipología constructiva que los muros de la Fase I pero no altera los muros perimetrales y de carga de ésta, a diferencia de lo que sí ocurre con las reformas vinculadas a la Fase III. Estas características concuerdan con los criterios seguidos a la hora de identificar las estructuras pertenecientes a esta fase en el conjunto del yacimiento, que se relaciona con la ocupación efectiva del recinto militar por parte de la cohors I Celtiberorum. A ella pertenecen una serie de reformas parciales cuyo objetivo es el acomodo de la unidad al espacio existente sin que suponga alteraciones sustanciales sobre el planteamiento edilicio original. Dado que la tipología constructiva empleada es muy similar a la del período anterior, resultó difícil la identificación de esta fase propuesta en anteriores aproximaciones como un conjunto cronológico unitario (COSTA GARCÍA 2010). Gracias al aporte del análisis espacial consideramos ahora que realmente se trata de una serie de reformas puntuales que podrían haberse sucedido en un período relativamente amplio de tiempo: división interna de ciertos espacios, repavimentación de otros o reparaciones puntuales. La datación de estos fenómenos es complicada pero por analogía con las reformas que sufren otros asentamientos militares hispanos como los de Rosinos de Vidriales (CARRETERO VAQUERO \& ROMERO CARNICERO 1996: 39-41; CARRETERO VAQUERO 1999: 54) o León (GARCÍA Y BELLIDO 1968: 19-21; 1970: 576-577; GONZÁLEZ FERNÁNDEZ \& VIDAL ENCINAS 2005) podría coincidir con un momento avanzado de la dinastía antonina, entre mediados y finales del siglo II $\mathrm{d}$. C.

\subsubsection{Fase III. Reestructuración edilicia}

Se vinculan a esta fase en el Sector 01 las

\footnotetext{
${ }^{12}$ A diferencia del esquisto que aflora localmente, el granito debió ser importado, quizá desde las canteras próximas del área de Guitiriz (Lugo).

${ }^{11}$ Aunque estamos llevando a cabo la caracterización de los morteros junto con su datación por OSL, los estudios anteriores apuntan a que están realizadas con arcilla local (CAAMAÑo GESTO 1984: 242; 1997: 270)
} 
UEM011 y UEM063. La segunda es un muro muy arrasado localizado en el interior del Edificio 3 sobre el nivel de uso romano de la Fase I, dispuesto en sentido norte-sur. Tiene una anchura de unos 40 $\mathrm{cm}$. La UEM011 es un muro con una planta en L invertida que se apoya en la UEM001; parte del extremo oeste del vano de acceso al Edificio 1, perpendicular al mismo, de tal forma que su trazado acorta el ancho original del deambulatorio de las Fases I y II (Fig. 10). Mide entre 51 y $54 \mathrm{~cm} \mathrm{de}$ ancho y presenta dos caras; está construido en mampostería de esquisto irregular con ripios de este mismo material y fragmentos de teja. En el encuentro con la fachada sur del edificio se dispone un sillar de granito reutilizado (Fig. 10), manteniéndose el aspecto constructivo-decorativo característico de la Fase I.
En el Sector 02 se vinculan a esta fase las UEM074, UEM078, UEM081, UEM092, UEM093, UEM095, UEM096, UEM102 y UEM105, que en su conjunto corresponden a la construcción de un nuevo espacio, el Edificio 4, entre los ya existentes 3 y 5 (Fig. 11), afectando al apéndice occidental del Edificio 5, que se reaprovecha como fachada sur del nuevo espacio de planta rectangular (12,5 x 29,6 m). Los muros miden $75-76 \mathrm{~cm}$ de ancho, pero como apenas conservan alzado es difícil determinar su aparejo. Se aprecia que tienen dos caras, así como el uso de mampuestos de esquistos irregulares o la ausencia de tizones. Adosados a la cara interior de los muros este y oeste se encuentran unos sillares de granito dispuestos a intervalos regulares, si bien algunos se han perdido o desplazado como consecuencia de reformas posteriores.
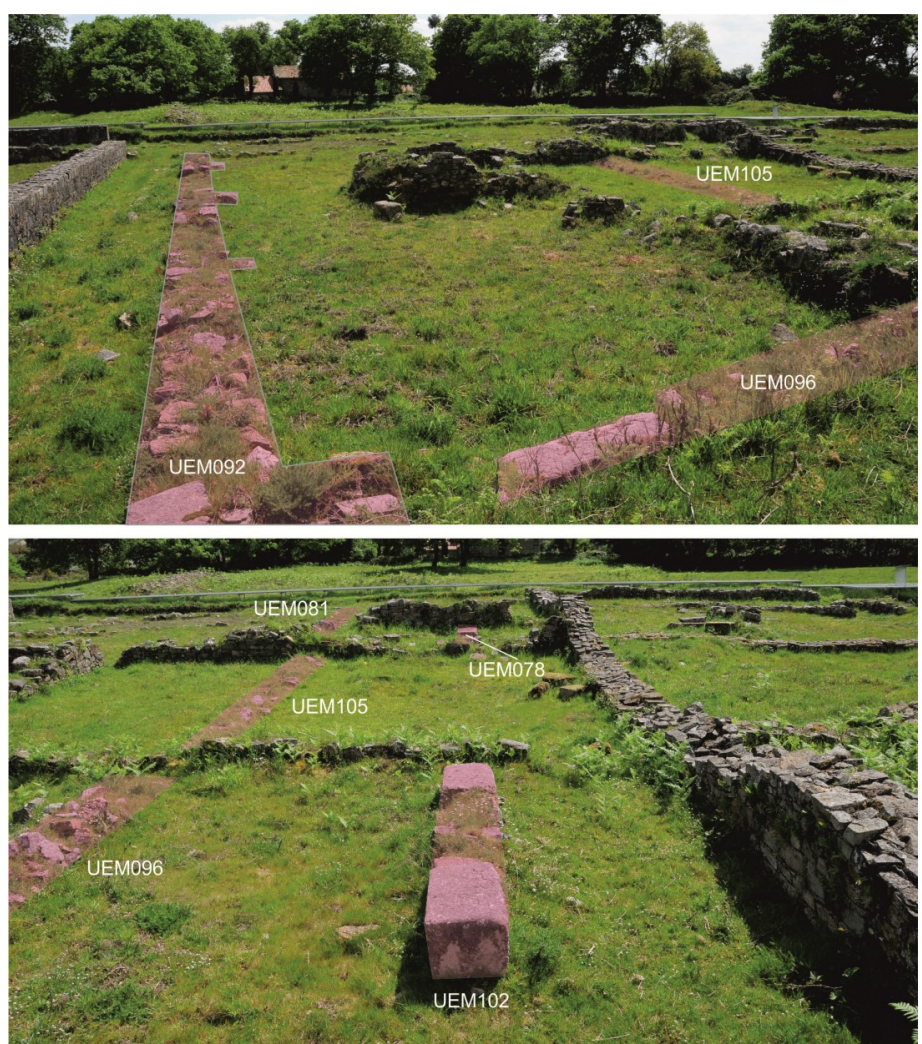

Fig. 11. Distintas UEM que conforman la Fase III en el Sector 02.

Fig. 11. Different UEM that constitute the Phase III in Sector 02.

De forma paralela a la fachada occidental del Edificio 4 se documentan asimismo los restos de tres muros (UEM074, UEM078 y UEM102) (Fig. 11) que parecen haber pertenecido a una misma estructura. En ellos se alternan tramos de mampostería de esquisto irregular con grandes sillares graníti$\cos (76-80 \times 46-47 \mathrm{~cm})^{13}$. Podría tratarse de un zócalo para el desarrollo en altura de una superestructura que sostendría una cubierta, generando al oeste del Edificio 4 un espacio porticado. La construcción de esta edificación habría alterado el recorrido original del canal UEM090-UEM094-UEM130, amortizándose su extremo septentrional para variar su trazado hacia el norte en línea recta (UEM095).

Esta fase se caracteriza por una intensa reestructuración del fuerte que altera su planteamiento constructivo original. Además de variar la factura de los muros y los materiales empleados, se realizan reformas que mudan significativamente las líneas de fachada de los edificios más antiguos y ocupan espa-

${ }^{13}$ Algunos han sido expoliados. 
cios anteriormente vacíos. Aún así, la modulación empleada sigue siendo romana y las estructuras mantienen la orientación original norte-sur y este-oeste, por lo que parece tratarse de una reforma de componente estrictamente militar que no implica la reocupación del fuerte por otro grupo humano. Estas transformaciones, que no tendrían por qué haberse producido al unísono, podrían vincularse al amplio período que se extiende entre finales del siglo II d. C. e inicios de la Tetrarquía, momento en que las evidencias de presencia militar en las fortificaciones hispanas comienzan a difuminarse de forma radical (CARRETERO VAQUERO \& ROMERO CARNICERO 1996: 44-45; CARRETERO VAQUERO 2000: 802; COSTA GARCÍA 2009b; 2013: 224 226). En Cidadela, las reformas apuntan hacia una intensificación de la actividad militar, tal vez relacionada con las mayores cotas de autonomía que durante el siglo III d. C. adquieren las unidades o bien con la transformación de la estructura logística del ejército en estos mismos años.

\subsection{Período tardorromano}

\subsubsection{Fase IV. Abandono del fuerte $y$} reocupación parcial

Únicamente documentamos esta fase en el Sector 01. Por un lado, las UEM015 y UEM022 son derrumbes de teja situados respectivamente bajo los muros UEM018 y UEM024. Se vinculan con la etapa de abandono de las estructuras militares cuya techumbre se habría desmoronado, construyéndose sobre el depósito nuevas estructuras en fases posteriores. El muro UEM037 (Fig. 3), situado en el interior del Edificio 1, tiene una orientación este-oeste y se apoya sobre el pavimento romano de la Fase I. Está muy arrasado y la única hilada conservada presenta doble hoja de mampuestos de esquistos y algún granito. La ausencia de tizones, que sí se observan en los muros de las fases posteriores, y la factura menos cuidada que la identificada en las construcciones de las Fases I a III nos llevan a situarlo en esta etapa, sin que podamos descartar totalmente su pertenencia a un momento anterior dada la ausencia de relación física directa con otras UEM.

Esta fase es de muy difícil definición e identificación. En diversas intervenciones se ha documentado una presencia minoritaria de materiales de tradición romana cuya datación puede encuadrarse en los siglos IV-VI d. C. (CAAMAÑo GESTO 1990b; VÁZQUEZ MARTÍNEZ 2005: 81; LÓPEZ PÉREZ 2006: 434-435). Por otra parte, en determinados lugares del recinto se registran depósitos relacionados con una breve reocupación del lugar tras la marcha de los soldados. Con todo, resulta complicado relacionar dichas evidencias con estructuras murarias concretas y las que hemos identificado con mayor claridad se encuentran fuera de los sectores de estudio seleccionados.

\subsection{Período tardoantiguo}

Como ya hemos señalado, las fases posteriores a la ocupación romana se integraban en estudios anteriores dentro de un único horizonte "postcampamental" (CAAMAÑO GESTO 1983; FERNÁNDEZ RODRÍGUEZ \& CAAMAÑO GESTO 1996; RAMIL GONZÁLEZ 2010). Se vinculaban a este horizonte depósitos de losas de pizarra resultado del derrumbe de cubiertas (Fig. 15), un genérico "nivel de abandono" artificial ${ }^{14}$, que en realidad se compone de varios depósitos, y un conjunto de piezas fundamentalmente cerámicas y metálicas- cuya tipología no se ajustaba al período romano. Esta interpretación consideraba que todos los depósitos correspondían a una ocupación puntual, lo que no coincide con los resultados de la lectura de paramentos, que sólo dentro de este período nos ha permitido identificar dos fases. Hemos constatado que el alcance de la reocupación del fuerte en este momento es mucho mayor de lo que se había barajado inicialmente. Se reparan, recrecen y doblan muchos de los antiguos muros romanos y, aunque esta actividad es especialmente acusada en las áreas más próximas a la uia principalis, existen indicios de una total ocupación del espacio por un grupo humano con intereses u objetivos distintos a los representados por el asentamiento romano precedente.

\subsubsection{Fase V. Reocupación del fuerte romano}

Se vinculan a esta fase en el sector 01 las UEM003, UEM014, UEM022, UEM029, UEM052, UEM059, UEM066, UEM069, UEM121, UEM122, UEM123, UEM124, UEM125 y UEM126. Buena parte de estas unidades se corresponde con reparaciones en los antiguos muros romanos, que bien son reconstruidos tras haber caído (vid. UEM122 en Fig. 9), bien doblados. Los muros tardoantiguos mantienen tanto la orientación como la anchura de los romanos, tienen las mismas partes -dos caras y relleno- y utilizan los mismos materiales que aquellos. Sin embargo se emplean más piezas de granito, que aparecen repartidas a lo largo de los lienzos y suelen presentar, por lo general, un módulo de mayor tamaño que el de los bloques usados en época romana. Se documentan tizones y fragmentos de teja en el relleno de los muros y, normalmente, las hiladas son mucho más irregulares.

Se construyen también algunos muros nuevos (UEM003) cuya modulación y orientación se ajustan a los usos romanos, pero no siempre respetan la división de los edificios del fuerte (Fig. 12). Las características son similares a las ya comentadas en el caso de las reconstrucciones, pero en estos la cimentación se localiza a una cota más elevada que en las estructuras romanas, sobresaliendo el zócalo unos $10 \mathrm{~cm}$ respecto a la cara del muro en alzado.

${ }^{14}$ Identificado como Nivel II (CAAMAÑo GESTO 1997: 267). 

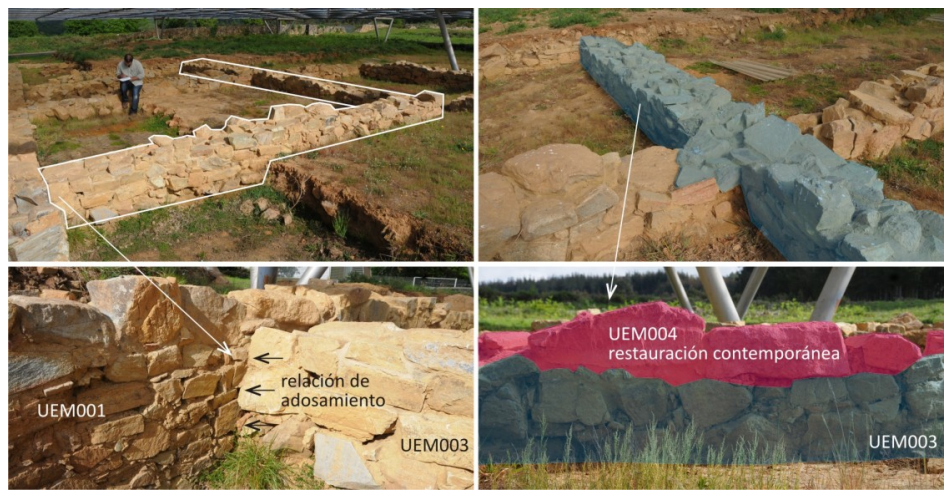

Fig. 12. Habitación construida en la Fase V en el Edificio 1, alterando el acceso al interior del mismo.

Fig. 12. Room built in the Phase $V$ of Building 1, altering the access to the interior.

Se vinculan a esta fase en el Sector 02 las UEM072, UEM080, UEM083, UEM084, UEM085, UEM091, UEM104, UEM106, UEM107, UEM108 y UEM110. Presentan las mismas particularidades formales que las ya descritas para el Sector 01, lo que nos permite suponer que se habría producido una reforma unitaria en todo el recinto. Se aprecia aquí el refuerzo de los muros de las fachadas sur y oeste del Edificio 4 con la clara finalidad de configurar un nuevo espacio que, paralelo a la uia principalis, se dividiría internamente en habitaciones rectangulares de distinto tamaño. Esta edificación se extendería hacia el este siguiendo la línea de fachada del Edificio 5, que queda fuera de los límites de este trabajo.

Más allá del recrecimiento de determinadas UEM pertenecientes a etapas anteriores lo más significativo de esta fase es una edificación de nueva planta que, adosándose a la fachada este del Edificio 3 y arrasando parte de los muros del Edificio 4, se extiende hacia el este adoptando en planta una forma rectangular (Fig. 13). Los muros de esta estructura conservan aún bastante altura y en ellos se aprecia una clara voluntad por imitar los aparejos romanos de la Fase I.
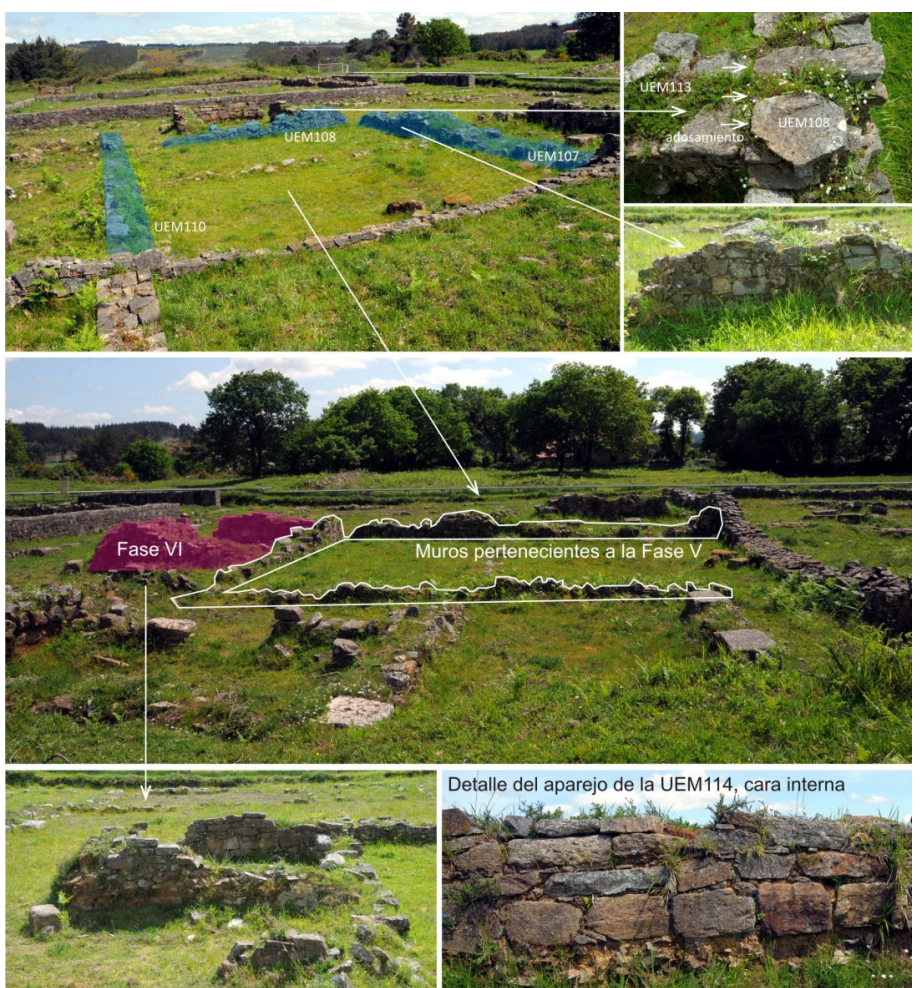

Fig. 13. Estructuras del Sector 02 que se han vinculado a las fases V y VI, que cortan el Edificio 4, y se han interpretado como posible iglesia. Detalles de los aparejos. Fig. 13. Structures of Sector 02 , related to phases V and VI. These structures cut the building 4 and have been interpreted as a possible church. Detail of the walls. 
Resta destacar dos cuestiones relativas a esta fase. En primer lugar, existe un elemento que en buena medida facilita la adscripción de determinadas UEM a la misma y es la relación existente entre éstas y los potentes derrumbes de lajas de pizarra. Estas piezas, que suelen aparecer agujereadas, han sido siempre identificadas como material de cubierta característico de época tardoantigua frente a las cubiertas de teja propias de los períodos romano y tardorromano. No existe en el entorno del yacimiento ningún afloramiento o cantera de esta clase de roca, por lo que, al igual que ocurría con el granito, debe considerarse una importación. En segundo lugar, en el caso de los pavimentos puede afirmarse que tanto el reaprovechamiento de viejos suelos -con reformas puntuales- como la construcción de nuevos pavimentos (enlosado, tierra batida o apisonada) coexisten en los espacios reutilizados en esta fase.

Aunque el ordenamiento general de las construcciones de este momento sigue el alineamiento maestro de las primeras fases romanas, la concepción del espacio es diferente. Como puede apreciarse en las figuras 7 y 8 , esta fase supone una reocupación y reordenación parcial de las estructuras de habitación vinculadas, sobre todo, al espacio de tránsito que conforma la uia principalis. En efecto, a medida que nos alejamos de ésta y nos adentramos en las partes traseras de los edificios que inte- gran los latera praetorii son menos habituales las estructuras, niveles y materiales vinculados a esta fase. Así, cobra fuerza la hipótesis de que en la primera fase tardoantigua se priorizaría la reocupación de las estructuras romanas de mayor entidad vinculadas a las zonas de tránsito interno, quizá pensando en un uso con fines residenciales. En otras zonas, sin embargo, las reformas pueden deberse a objetivos distintos. Teniendo en cuenta el contenido de los rellenos artificiales localizados en el interuallum (CAAMAÑo GESTO 1997: 267), sugerimos que su deposición serviría a la creación de un espacio intramuros para labradío o huerta como proponen Costa García y Varela Gomes (2011: 188; ver también Costa GARCÍA et al. 2012: 462). Somos conscientes de que resulta muy complicado contrastar estas hipótesis y ofrecer una visión de conjunto de lo que ocurriría en el antiguo recinto militar en estos momentos, considerando que el yacimiento sólo ha sido excavado parcialmente y siguiéndose distintas metodologías.

En cuanto a la datación de esta fase, y a la espera de los resultados del análisis por OSL de los morteros, los únicos elementos que permiten una aproximación cronológica son las mencionadas hebillas metálicas datadas en el siglo VII d. C. (CAAMAÑo Gesto 1983; 1991; RAMIL GONZÁLEZ 2007) (Fig. 14).

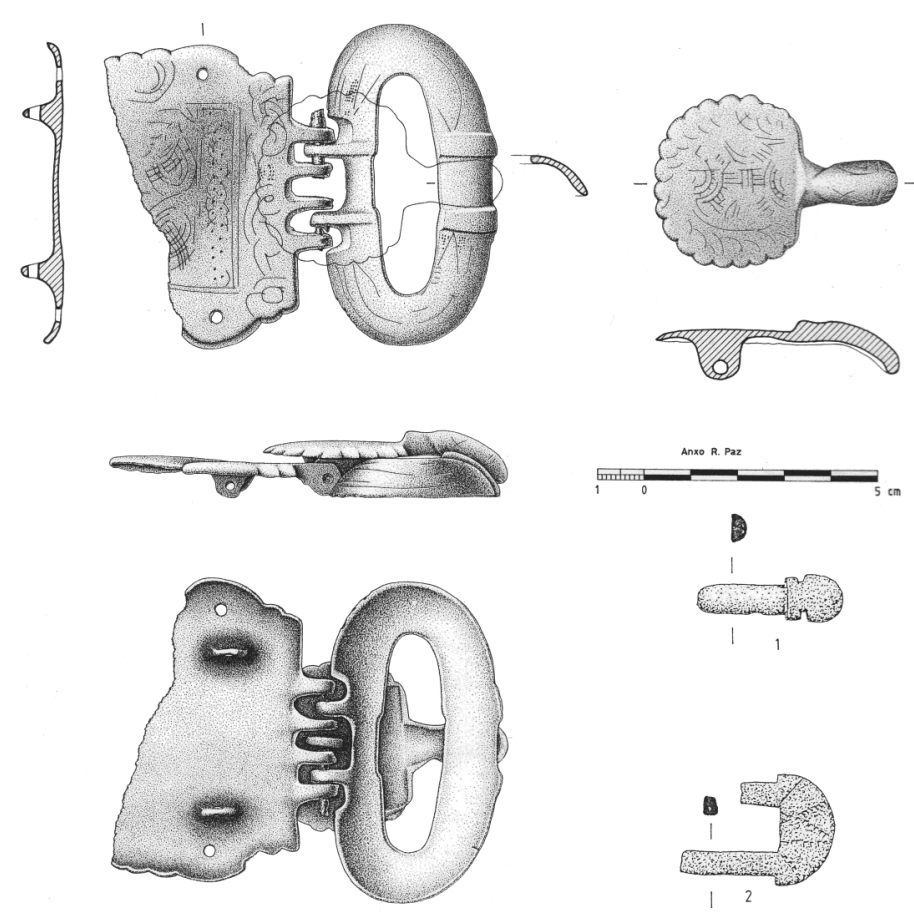

Fig. 14. Hebillas de cinturón en bronce halladas durante las campañas de excavación de 1983 (abajo derecha) y 1991 (restantes). Dibujos de Anxo Rodríguez Paz (CAAmaño Gesto 1983 y 1991).

Fig. 14. Bronze buckle found during the excavations of 1983 (down right) and 1991 (the rest). Drawings by Anxo Rodríguez Paz (CAAMAÑo Gesto 1983 and 1991). 


\subsubsection{Fase VI. Reforma y ampliación del conjunto tardoantiguo}

A esta fase se vinculan en el Sector 01 las UEM044, UEM47, UEM48 y UEM54, mientras que en el Sector 02 corresponden las UEM086, UEM087, UEM088, UEM098, UEM099, UEM100, UEM101, UEM103, UEM113, UEM114, UEM116 y UEM117. Han sido las evidencias recogidas en el segundo sector las que nos han permitido definir la existencia de dos momentos en este periodo.

Las UEM del Sector 02 se agrupan en cuatro actividades: una canalización abierta en la fachada meridional del Edificio 4 -que afecta a las UEM079 (Fase I) y UEM080 (Fase V)-; una habitación construida en el esquinal noroeste de esta misma edificación que se divide en dos espacios comunicados a través de un vano; una sepultura de lajas de pizarra, cabecera de granito y orientación oeste-este situada dentro de la edificación rectangular construida durante la Fase V; y una pequeña estancia de planta cuadrangular (Fig. 13) que se adosa por el este a esta misma construcción (UEM107, UEM108 y UEM110).

Para la comprensión integral de esta Fase VI resulta fundamental hacer hincapié en la relación que existe entre esta pequeña estancia y la edificación rectangular anterior. Aunque anteriormente ambos espacios habían sido interpretados como pertenecientes a una única fase, la lectura de paramentos permite observar el adosamiento existente entre ellos y sus diferencias constructivas. Los muros de la Fase V son más estrechos $(60-62 \mathrm{~cm})$ que los de la VI $(70-80 \mathrm{~cm})$ e imitan el aparejo romano, mampostería irregular dispuesta en hiladas y pseudohiladas que emplea de forma casi exclusiva el esquisto. Sólo en los esquinales sureste y noreste se usan sillares graníticos hoy desaparecidos. Los muros de la Fase VI presentan en su cara interna un sillarejo de hiladas regulares (Fig. 13) que mezcla esquistos y granitos; abundan además los tizones de granito. Los muros exteriores están prácticamente perdidos; en el norte y el sur se observa el relleno de tierra y mampuestos. En su cara este se aprecia que el muro estaba forrado en su parte baja por sillares de granito y esquisto que sobresalían entre 21 y $22 \mathrm{~cm}$ de la línea de fachada. Se apoya a su vez sobre un zócalo también de piedra de gran tamaño que sobresalía entre 10 y 15 $\mathrm{cm}$. Los esquinales tendrían también sillares de granito, el situado al sudeste fue expoliado y el noreste se encuentra caído al lado de su ubicación original. Por último, conviene señalar que este espacio se encuentra a mayor altura que el suelo de uso de Fase $\mathrm{V}$ y en su conjunto los muros se asientan sobre tierra, lo que difiere del tipo de cimentación documentado para la fase anterior.

La estructura resultante de la suma de estos dos espacios ha sido interpretada como una posible iglesia, hipótesis que consideramos bastante acertada. En primer lugar, la edificación ocupa una posi- ción central con respecto a las restantes estructuras de este período, lo que nos lleva a plantear la hipótesis de que se articulan en torno a un posible lugar de culto. En planta se puede reconocer una nave principal de mayor tamaño y un pequeño ábside que no sólo marca la orientación del edificio hacia el este, sino que además cuenta con un suelo sobreelevado y un cuidado aspecto exterior. La presencia de una tumba en el interior del edificio bajo el pavimento de la nave resulta muy llamativa.

Mayor dificultad presenta la interpretación de las estructuras del Sector 01, puesto que son elementos algo más fragmentarios. En el muro UEM046 de la Fase I se habrían practicado una serie de cortes con el fin de asentar otra tumba (UEM044) con cabecera y pies de granito, laterales de lajas de pizarra y una orientación oeste-este. Próxima a la tumba, entre los Edificios 1 y 3 se ubicaría una estructura de planta en U cuyas características constructivas, orientación -oeste-este- y forma en planta se asemejan, en una menor escala, a las que acabamos de describir para el pequeño espacio del Sector 02. La proximidad de la tumba y sus similitudes con el mencionado ábside, hacen que nos planteemos la hipótesis, no conclusiva, de que contasen con una función y cronología similares.

La presencia de dos posibles iglesias podría apoyar la interpretación del conjunto tardoantiguo, al menos en la segunda fase, como cenobio o complejo monacal, si bien es necesario continuar la investigación de manera que pueda contrastarse fehacientemente esta teoría. Es imposible por el momento ofrecer una datación segura de la Fase VI, puesto que las evidencias disponibles sólo nos permiten considerarla perteneciente a un momento más avanzado del siglo VII d. C que el de la Fase V.

\subsection{Período Altomedieval}

\subsubsection{Fase VII. Ocupación puntual}

Contamos con suficientes indicios para considerar la existencia de otra fase de ocupación de cierta entidad tras un momento de abandono que viene evidenciado por el derrumbe de los muros y las cubiertas de las estructuras tardoantiguas. Aunque esta fase fue documentada fundamentalmente en el ámbito meridional del Edificio 1, las excavaciones más recientes evidencian su presencia en otras áreas del yacimiento (RAMIL 2010). Se vinculan a la misma las UEM016, UEM017, UEM018, UEM023, UEM024, UEM053, UEM055, UEM056, UEM062 y UEM064 del Sector 01 Básicamente se corresponden con derrumbes de las cubiertas de pizarra, la capa de tierra que los cubre (UEM016, UEM017, UEM023) y una serie de muros que bien se construyen sobre estos niveles de abandono (Fig. 15) o bien se asientan sobre pavimentos y estructuras de fases anteriores (UEM018 y UEM024). 


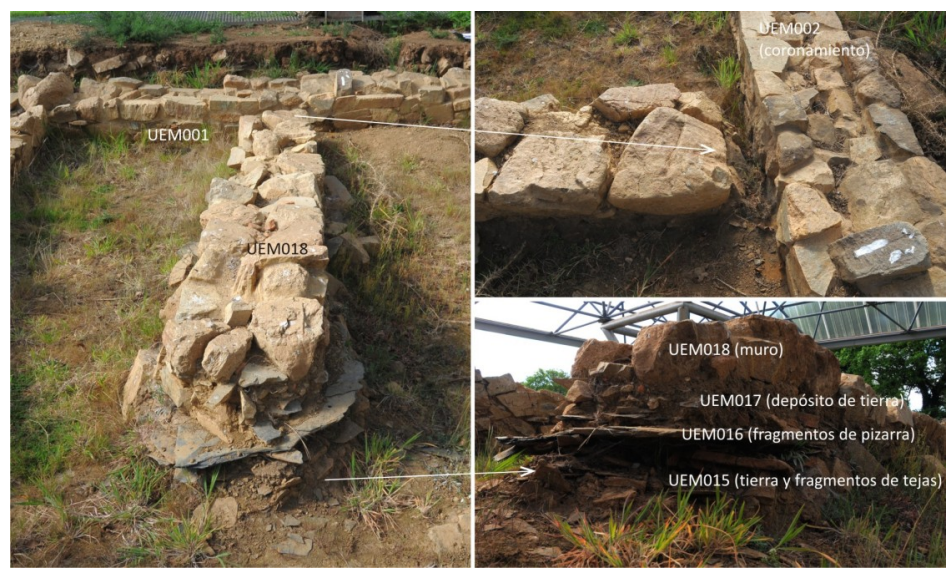

Fig. 14. Muro construido en el interior del Edificio 1 que ha sido identificado como altomedieval. Este se apoya sobre diferentes depósitos de derrumbes de las fases tardorromana y tardoantiguas.

Fig. 14. Wall built in the interior of Building 1, linked to the early medieval period. This wall stands over the collapse of late roman and late antique phases.

Los muros de esta fase difieren de lo visto en momentos previos: reutilización indistinta de materiales de construcción, ausencia de argamasa, anchura irregular, muros ondulantes, despreocupación por mantener un orden estético, ausencia de cimentación, etc. Asimismo se aprecia una ruptura con la articulación espacial de las fases previas: el reaprovechamiento de viejas estructuras semeja ahora un fenómeno residual, se rompe la ortogonalidad establecida en época romana y respetada durante el período tardoantiguo. Debe señalarse que los restos de este período, al encontrase a una cota superior, se han visto más afectados por causa de las actividades agropecuarias que se han desarrollado en el lugar hasta hace pocos años.

Resulta muy complicado interpretar la funcionalidad o cronología de esta fase. Parece existir una ruptura efectiva con el período anterior y la reutilización de un sarcófago pétreo como material constructivo resulta especialmente indicativo (COSTA GARCÍA \& VARELA GÓMEZ 2011: 191-192) ${ }^{15}$. Con todo, el único material que por el momento podría ayudarnos a datarla es un fragmento de cerámica vidriada procedente de un taller del sur de la península -CID06-199, 201- cuya cronología se ha fijado en los siglos IX-XI d. C. (RAMIL GONZÁLEZ 2006).

\subsection{Período posmedieval}

Aunque no las analizaremos en detalle, apuntamos la existencia de otras dos fases documentadas durante la lectura de paramentos.

\subsubsection{Fase VIII - Parcelación y expolios}

A esta fase vinculamos los restos de estructuras de funcionalidad desconocida. Es el caso de un ancho muro que se situaba a una cota bastante su- perficial sobre el Edificio 4 y que fue eliminado al excavarse éste. Probablemente se trataba de un vallado moderno o contemporáneo. El expolio de materiales del yacimiento, sobre todo de los sillares de granito empleados en los esquinales y crujías de los muros, se produce desde época históri$\mathrm{ca}^{16}$ hasta tiempos muy recientes (COSTA 2014b: 111). La realización de zanjas para la extracción de materiales o la apertura de pasos para el ganado en las murallas ha sido datada en algunos casos merced al hallazgo de elementos singulares, como una moneda de finales del siglo XIX (CAAMAÑO GESTO 1990a) o una chapa de refresco de finales del siglo XX (RAMIL GONZÁLEZ 2009).

\subsubsection{Fase IX - Intervenciones contemporáneas}

Se incluyen las afecciones al yacimiento producidas en época contemporánea, sean resultado de la práctica de distintas actividades de explotación del terreno o se deban al desarrollo de las intervenciones arqueológicas que han tenido lugar a lo largo de los siglos XX y XXI.

\section{VALORACIONES PRELIMINARES SOBRE LAS FASES POSROMANAS. A CIDADELA, ¿UN CENTRO DE PODER EN LA GALICIA TARDOANTIGUA?}

Como ya se ha indicado, no estamos en condiciones todavía de presentar interpretaciones generales sobre la evolución del yacimiento de A Cidadela. En todo caso, sí podemos esbozar, para finalizar este artículo, algunas ideas de trabajo en base a los datos disponibles hasta el momento, incidiendo fundamentalmente en las fases tardoantiguas, ya que son las que interesan más directamente al proyecto EMCHAHE en el que esta revisión se enmarca y las que han recibido habitualmente me-

\footnotetext{
${ }^{15}$ Cabría plantearse si tanto este sarcófago como otro aparecido en 1934 en el Edificio 3 (CosTA 2014b: 118) pertenecen a alguna de las fases tardoantiguas analizadas o si acaso corresponden a una necrópolis posterior a este horizonte pero anterior al que nos ocupa.
}

${ }^{16}$ Como lo demuestra la reutilización de algunos de estos sillares en los enlosados de época tardoantigua (RAmIL 2010). 
nos atención por parte de la historiografía. A este respecto, no repetiremos el contenido del reciente análisis de las mencionadas fases posromanas del yacimiento realizado por Costa García y Varela Gómez (2011), sino que lo tomaremos como punto de partida para avanzar algo más en la interpretación de este lugar durante el período tardoantiguo.

Los resultados preliminares de los análisis realizados sugieren que las secuencias del llamado período "tardoantiguo" (Fases V y VI) en el yacimiento de A Cidadela no son una mera reocupación residual de los antiguos restos romanos, como hasta ahora se había entendido, sino que poseen unas dimensiones y características muy destacables que nos llevan a hablar de una etapa de gran importancia no solo en la historia del yacimiento, sino también a nivel de entendimiento de las dinámicas sociopolíticas de la Tardoantigüedad en Galicia. Aunque aún queda mucho trabajo por realizar, es posible apuntar, de manera hipotética y provisional, a que A Cidadela constituyó en este período un verdadero "lugar central" o "centro de poder" de la Galicia tardoantigua. Nos basamos, siguiendo la propuesta formulada por Quirós Castillo y Fernández Mier (2012) sobre el grado de inversión arquitectónica y material como indicadores sociopolíticos, en los siguientes datos:

1. En primer lugar, se ha demostrado que las reocupaciones de este período son mucho más importantes y extensas de lo que se pensaba. Esto implica un grado de inversión relativamente elevado, así como una alta capacidad de movilizar recursos económicos y una cadena de producción artesanal de cierta entidad que escapa al ámbito local: abastecimiento de materiales, personal especializado con conocimientos técnicos, etc. (QUIRÓs CASTILlO \& FERNÁNDEZ MIER 2012: 33-42). Todo ello nos indica, pues, que estamos ante ocupantes con una cierta capacidad de inversión económica.

2. En segundo lugar, es interesante la constatación del suministro de la pizarra para su uso como material de cubierta. Ésta hubo de traerse probablemente desde las canteras de O Incio, situadas a más de $100 \mathrm{~km}$ en el sur de la provincia de Lugo (COSTA GARCÍA \& VARELA GómeZ 2011: 183). Nuevamente esto implica la existencia de un circuito de intercambio, que a tenor de los datos actualmente disponibles, es específico de este período -no se documenta en la fase altomedieval-, y que implica una mínima demanda así como la capacidad económica de los ocupantes de A Cidadela para costear su transporte.

3. También se ha propuesto aquí la existencia de dos iglesias, frente a los estudios anteriores que solo identificaban una en este período. Como es sabido, las iglesias son importantes instrumentos que acompañan, refuerzan y legitiman al poder en este período. Hay que recordar que en los siglos VI -VII existía una clara regulación sobre las fundaciones de iglesias, lo que implicaba que los fundadores debían poseer una mínima riqueza. Así, en los Concilios V y XVI de Toledo se indica que la dotación para poder fundar una iglesia debía ser de, por lo menos, diez esclavos o siervos, así como espacios suficientes de monte, huerto y labradío (CARBAJAL Sobral 1999: 245). Igualmente, los concilios insisten en que iglesias estuviesen suficientemente dotadas para el servicio del público alumbrado, ropas sagradas, libros, servidores...- y en que se debían pagar las "tercias" correspondientes a los obispos. Pero, además de la riqueza necesaria para construir al menos una iglesia en este lugar, hay que señalar los templos constituyen en sí mismos verdaderos instrumentos de poder, que, entre otras funciones, permitían intervenir en el dominio del territorio, evitar la disgregación de las propiedades familiares, posibilitar la captación de nuevos bienes y donaciones, y reforzar ideológicamente el dominio de sus propietarios (LORING 1987: 89).

4. En cuarto lugar, debemos hacer mención a los materiales arqueológicos hallados en esta fase tardoantigua. Aunque en este trabajo no se ha abordado el estudio de los mismos ${ }^{17}$, trabajos previos ya han señalado que a este período corresponden algunas producciones de cerámica fina importada que evidencian contactos a larga distancia y un nivel económico alto entre los ocupantes del lugar. Como indica Juan Naveiro López (1991) y más recientemente Adolfo Fernández Fernández (2011: 639,683 ) en A Cidadela aparecen sigillatae africanas del siglo IV de los tipos C y D que indican que las vías de suministro costa-interior funcionaban aún entonces, y también cerámicas de la primera mitad del siglo VI como ánforas orientales LRC. Por su parte, Catalina López Pérez y Mario César Vila (2009: 49) añaden que en este yacimiento se localizan también THST, TSFT, que indican contextos del IV y del VI-VII respectivamente -si bien Fernández descarta que lleguen cerámicas de importación a este lugar a partir de mediados del siglo VI-. En este sentido, hay que destacar que A Cidadela, junto con Lugo, sería el único yacimiento identificado del interior de Galicia que en siglo VI recibe cerámicas de importación orientales. Esto nos pone de nuevo sobre la pista de un poder de amplio alcance residiendo en este lugar. En cuanto a los fragmentos de hebillas de bronce, no podemos afirmar que sean necesariamente indicativos de la presencia de élites sociales, pero parece ser habitual que estos hallazgos se asocien con los sectores de alto estatus (YZQUIERdo PERRín 1993: 6768). Finalmente, cabe hablar de los vidrios, muchos

${ }^{17} \mathrm{El}$ estudio de los materiales cerámicos posromanos de este yacimiento está muy poco desarrollado, especialmente con respecto a la cerámica común detectada (Ramil 2010), pese a que esto podría mejorar mucho la compresión del mismo. 
de los cuales semejan ser producciones tardías con paralelos en otros yacimientos coetáneos de la región galaica (CAAMAÑo GESTO 1990b; VÁZQUEZ MARTíNEZ 2005: 81).

5. Igualmente cabe señalar que en este período A Cidadela -o su asociado uicus de Insua- seguía siendo cabeza de un territorio denominado "Cohortis"18. Al margen de que su entidad y naturaleza pudiese haber cambiado con respecto al espacio de época romana, su existencia pervive en las centurias siguientes, tal y como atestigua la documentación de los siglos IX-X (COSTA GARCíA \& VARELA GómEZ 2011). El análisis de los límites parroquiales actuales nos permite proponer algunas hipótesis al respecto. Partiendo de los estudios de F. López Alsina sobre la "parroquia antigua" en Galicia (LÓPEZ ALSINA 1999), es posible pensar que el territorio de Curtis comprendiese originariamente el espacio de las actuales parroquias de Santaia de Curtis, San Vicente de Curtis y Santa María de Ciadella -situada en medio de ambas, como testimonio de su antigua posición de cabeceraTeniendo en cuenta que la iglesia de Santaia de Curtis fue fundada por un aristócrata llamado Placentio (propietario de la villa Chacente, muy próxima al yacimiento) probablemente a inicios del IX, tal y como nos informa un documento del año 995 (Loscertales De García de VALDEAVELlano 1976: vol. I, doc. 137), podemos pensar que al menos desde ese momento el antiguo territorio de Curtis ya se encuentra fragmentado y que habría perdido su valor o función previa. Sabemos además, por ese documento, que este mismo Placentio también funda o restaura la cercana iglesia de Santa María de Ciadella, situada a escasos metros, aunque fuera, del antiguo recinto militar romano, y que a fines del siglo $\mathrm{X}$ esa iglesia aun pertenecía a su familia, lo que de nuevo refuerza la idea de que el lugar de A Cidadela a inicios del siglo IX llevaba ya abandonado un tiempo. El hecho de que la fragmentación del territorio de Curtis no se produzca hasta los siglos VIII-IX parece apoyar la idea de que con anterioridad todavía poseía algún tipo de función, siendo muy probablemente A Cidadela su cabecera.

6. Por último, el análisis estratigráfico realizado nos permite afinar algo más las características y evolución de este lugar, entendido como un centro de poder, en el período tardoantiguo. Como se ha señalado, se pueden distinguir dos fases $(\mathrm{V}$ y VI) dentro de éste. En un trabajo anterior se había propuesto interpretar la reocupación del fuerte romano en este momento como un complejo cenobítico, debido principalmente a la distribución y organización de los espacios que rodean a la probable iglesia (COSTA GARcía \& VARELA GÓMEZ
2011). Sin embargo, como hemos visto, el ábside de dicha iglesia corresponde a una segunda etapa (Fase VI), mientras que las estancias referidas pertenecen a un momento anterior (Fase V). Por lo tanto, podemos pensar que la función religiosa del lugar se adquiere en esa segunda etapa. Para la primera fase del período tardoantiguo, en la que se levantan y recrecen los muros romanos (siglo VIinicios del siglo VII), barajamos la hipótesis de que el lugar podría haber mantenido una función principal muy similar a la de época romana, es decir, un lugar fortificado que se sirve de las potentes murallas del lugar; en definitiva el refugio de un poder militar con una función de control territorial y viario estratégico. Esto es lo que parece indicar ese mantenimiento cuidadoso de la morfología y organización del lugar con respecto al uso militar romano. Esta idea ya ha sido expuesta por Felipe Arias Vilas (1994: 55), quien considera que la reocupación de A Cidadela debe entenderse como la de un campamento de llanura, quizá temporal, en el contexto del reino suevo-visigodo. Según esto, sería en un segundo momento cuando el lugar (o parte del mismo) adquiere esa función religiosa iglesia o monasterio y tumbas en torno- que ya ha sido estudiada en trabajos anteriores (COSTA GARCÍA \& VARELA GÓMEZ 2011), sin que esto impida que siguiese ejerciendo también un papel militar o estratégico.

En base a todo lo visto hasta el momento, podemos establecer que en el "período tardoantiguo", concretamente entre los siglos VI y VII, A Cidadela fue objeto de una inversión arquitectónica que refleja un poder de cierta envergadura detrás de la misma. ¿De qué tipo de poder estamos hablando exactamente? Aunque no es posible responder a esta pregunta con los datos actualmente disponibles, sí podemos señalar algunas hipótesis de trabajo con base en lo que conocemos del contexto histórico de este período.

Los paralelos de otras zonas de Europa indican que durante la Tardoantigüedad las ruinas de edificios públicos de época romana -incluidas las estructuras militares-, estaban muy a menudo controladas por las autoridades (BRENK 1987: 106). Esto se debía no solo a su valor material o estratégico sino también al potencial de legitimación ideológica que ofrecían como símbolos del antiguo poder imperial romano (EATON 2000: 128-129). En este sentido, el claro valor estratégico y militar que A Cidadela mantenía en la estructura viaria y territorial de la Galicia tardoantigua, unido a la continuidad que arquitectónicamente manifiesta el yacimiento en este período con respecto al modelo romano -incluida la imitación de las técnicas constructivas-, nos permiten pensar, siempre como hipótesis provisional, que las élites que reocuparon A Cidadela en este período mantenían algún tipo de

${ }^{18}$ En caso genitivo singular, "de la cohorte", hoy Curtis. 
conexión con las máximas autoridades del momento, es decir, con la monarquía suevo-visigoda.

Recientes investigaciones muestran de manera cada vez más clara que la estructura política de la monarquía sueva y visigoda se basaba en el diálogo y la negociación -no siempre por medios pacíficosentre el poder central -pero limitado- de los reyes, y las élites locales: aristócratas, señores militares, obispos... que precisaban de la legitimación y amparo de la monarquía (CASTELlanos \& MARTín VISO 2005). A nivel territorial, la arqueología de los últimos años está tratando de comprender cuales eran esos lugares de encuentro entre el poder central y el local (GUTIÉRREZ GONZÁLEZ 2011). En el caso de Galicia, sólo tenemos algunas evidencias de cómo y dónde se podía producir esa articulación entre ambas esferas. Se trata de ciudades principales comoLugo, donde como atestigua la presencia de un "dux" del rey visigodo a mitad del siglo VII llamado Dogilano (DÍAZ Y DÍAZ 1974: 89), o Tui, donde se asienta temporalmente la corte del rey Witiza a finales del mismo siglo (DíAz MARTÍNEZ 2011: 251). Las fuentes textuales del período también dejan entrever el control directo de la monarquía ciertas propiedades en el noroeste peninsular, como indica la Autobiografía de Valerio, cuando se señala cómo la hostilidad del rey cayó sobre la familia del rico propietario Ricimer, que fue expulsada -probablemente por el rey Wamba, quizá por alguna infidelidad cometida contra el soberano-, de la propiedad llamada "Ebronanto", situada en el Bierzo (FrighetTo 2006: 103-106). También hay que citar recintos fortificados como Penadominga (Quiroga), un espolón situado en un emplazamiento muy prominente sobre el río Sil, en el que se localizaron dos placas de cinturón de bronce de tipo visigodo fechables entre los siglos VI-VII (YZQUIERDO Perrín 1993: 66); o Penedos do Castro (Nogueira de Ramuín), probable castro con reocupación en este período (LAMAS 2008) y en el que existe una inscripción que parece corresponder a la un duque del rey visigodo Leovigildo, en torno al 585 (Freire CAMANIEL 1989). Por último no hay que olvidar los lugares de acuñación de moneda y organización administrativa, que a menudo correspondían con centros eclesiásticos (DíAZ MARTíneZ 2011: 196-206; SÁNCHEZ PARdo 2014).

Consideramos, por tanto, que las reocupaciones de A Cidadela durante época tardoantigua, genéricamente entre los siglos VI y VII podrían entenderse en el marco de estos puntos de articulación entre la monarquía suevo-visigoda y las élites locales. Sin embargo, a la luz de lo que hemos comentado, A Cidadela conforma un tipo de lugar diferente a los constatados hasta ahora, ya que se trataría de la única reocupación de un asentamiento militar romano que conocemos en el Noroeste si omitimos el particular caso de la ciudad de León (Avello Álvarez 1991) $^{19}$. En este contexto, A Cidadela debió jugar un papel importante, por dos razones. Primeramente, por su posición estratégica en la geografía del noroeste peninsular. En este sentido, es posible que A Cidadela pueda estar relacionada con otra serie de lugares fortificados algunos surgidos ex novo, otros reocupando antiguos sitios romanos- que comienzan a conocerse en Galicia y que nos hablan de una articulación territorial mucho mayor de lo pensado para estos momentos en el Noroeste (SÁNCHEZ PARDO 2013). En segundo lugar, por la creación de un espacio eclesiástico, probablemente en algún momento del siglo VII. Sabemos por diversos textos que este fenómeno no es raro en este momento, ya que por todo el Noroeste peninsular se constata en este siglo un importante auge de fundaciones eclesiásticas por parte de las aristocracias, debido, sobre todo, a la fuerza y peculiaridad del mundo monástico y su impulso por parte de destacadas figuras como San Fructuoso (DÍAZ Y DÍAZ 1974; DÍAZ MARTÍNEZ 2011: 242; SÁNCHEZ PARDO 2013). A nivel arqueológico es interesante señalar el paralelismo que presentan las fases tardorromanas y tardoantiguas de Cidadela con el caso, bien conocido y estudiado, de la villa romana de Veranés (Gijón) sobre la que también se construye un espacio eclesiástico en época tardoantigua, o al menos antes del siglo IX (FERNÁNDEZ OCHOA et al. 2005-2006). Aunque peor conocidas, gran parte de las iglesias tardoantiguas constatadas arqueológicamente en Galicia, también se superponen a antiguas estructuras romanas, como sucede en los casos de Adro Vello (O Grove), construida sobre una antigua villa y factoría romana de salazón y una posterior necrópolis (CARro Otero 1987); o San Xiao de Trebo (Cariño), edificada sobre un asentamiento agrario y/ o pesquero tardorromano (RAMIL GONZÁLEZ \& LÓPEZ LOUREIRO 2003).

\section{CONCLUSIONES}

La completa revisión de las secuencias estratigráficas conocidas en el yacimiento de A Cidadela, combinada con la lectura estratigráfica de los paramentos conservados nos ha permitido obtener una visión mucho más clara, y en muchos aspectos, matizada, de la evolución de este yacimiento. Aunque se trata de resultados preliminares y resta todavía mucho por estudiar, parece claro que se trata de un yacimiento de enorme interés no solo para el período romano (como ha sido concebido hasta

\footnotetext{
${ }^{19}$ Otros recintos militares de época altoimperial en ningún caso serían reocupados tras su abandono. Tanto en Bande (Ourense) (RoDRíGUEZ COLMENERO 2006a: 66-68) y Herrera de Pisuerga (Palencia) (Morillo CERDÁn et al., 2006) a partir de mediados del siglo II d. C. como en Rosinos de Vidriales (Zamora) (CARRETERo VAquero \& Romero CARNICERo 1996: 44-45; CARRETERo VAQUERo 2000) desde mediados-finales del siglo III d. C. se amortiza el espacio y se procede a la extracción de materiales constructivos. Los cercanos uici civiles, sin embargo, presentan fases de ocupación que se adentran en el periodo tardorromano (COSTA GARCíA 2013)
} 
ahora) sino para entender diferentes aspectos clave (poder, economía, geopolítica...) de la historia del Noroeste peninsular en los siglos siguientes.

\section{AGRADECIMIENTOS}

Queremos expresar nuestro sincero agradecimiento a profesor Marco García-Quintela (USC) su apoyo para la implementación del proyecto EMCHAHE en la USC. Al profesor José Manuel Caamaño Gesto (USC) por la información proporcionada sobre las distintas intervenciones arqueológicas llevadas a cabo bajo su dirección. A Anxo Rodríguez Paz (Incipit, CSIC) quien efectuó los dibujos de las intervenciones de las décadas de 1980 y 1990, por el material proporcionado a este estudio. Y finalmente, a los revisores anónimos de este artículo, que con sus sugerencias han ayudado a mejorarlo

\section{BIBLIOGRAFIA}

ARIAS VILAS, F. 1994. O proceso de xermanización. In: E. RAMIL REGO (Coord.), El mundo romano en Galicia, Lugo, Museo de Vilalba: 49-63.

Avello Álvarez, J. L. 1991. Los suevos y visigodos en la provincia de León. Memorias de Historia Antigua, 11-12: 295-316.

Blanco-Rotea, R. 2007. Asesoría técnica a la excavación arqueológica y consolidación del Castro de Borneiro (Cabana de Bergantito, A Coruña). Informe sobre la lectura estratigráfica. Informe inédito. Santiago de Compostela, Laboratorio de Patrimonio, CSIC.

Blanco-Rotea, R. \& MAÑana-BorRazÁs, P. 2010 Levantamento volumétrico e lectura de alzados das estructuras escavadas. Memoria de revalorizacion dos restos do Castro de Vigo. Volume III. Memoria inédita. Santiago de Compostela, Laboratorio de Patrimonio, CSIC.

BRENK, B. 1987. Spolia from Constantine to Charlemagne Aesthetics versus Ideology. Dumbarton Oaks Papers, 41: 103-109.

CaAmaño Gesto, J. M. 1983. Memoria Técnica de Excavación en el campamento romano de Cidadela (Sobrado dos Monxes. Coruña). Memoria inédita Santiago, Dirección Xeral do Patrimonio Cultural, Consellería de Cultura e Turismo, Xunta de Galicia.

CAamaño Gesto, J. M. 1984. Excavaciones en el campamento romano de Cidadela (Sobrado dos Monxes. Coruña). Memoria preliminar de la campaña de 1981. NAH, 18: 233-254

CAAMAÑo Gesto, J. M. 1987. La cohors I Celtiberorum y su campamento de Cidadela (Sobrado dos Monxes - Coruña). Cuadernos de Estudios Gallegos, XXXV: 71-78.

CaAmaño Gesto, J. M. 1989a. Memoria Técnica de Excavación en el campamento romano de Cidadela (Sobrado dos Monxes. Coruña). Memoria inédita. Santiago, Dirección Xeral do Patrimonio Cultural, Consellería de Cultura e Turismo, Xunta de Galicia.

CaAmaño Gesto, J. M. 1989b. Estampillas de la Cohors I Celtiberorum halladas en el campamento romano de Cidadela. Gallaecia, 11: 209-229.

Caamaño Gesto, J. M. 1990a. Memoria Técnica de Excavación en el campamento romano de Cidadela (Sobrado dos Monxes. Coruña). Memoria inédita. Santiago: Dirección Xeral do Patrimonio Cultural, Consellería de Cultura e Turismo, Xunta de Galicia.
CAAMAÑo GeSto, J. M. 1990b. Vidrios hallados en el campamento de Cidadela (Sobrado dos Monxes - A Coruña). Gallaecia, 12: 177-190.

CaAmaño Gesto, J. M. 1991. Memoria Técnica de Excavación en el campamento romano de Cidadela (Sobrado dos Monxes. Coruña). Memoria inédita. Santiago, Dirección Xeral do Patrimonio Cultural, Consellería de Cultura e Turismo, Xunta de Galicia.

CaAmaño Gesto, J. M. 1992. Memoria Técnica de Excavación en el campamento romano de Cidadela (Sobrado dos Monxes. Coruña). Memoria inédita. Santiago, Dirección Xeral do Patrimonio Cultural, Consellería de Cultura e Turismo, Xunta de Galicia.

CaAmaño Gesto, J. M. 1993. Memoria Técnica de Excavación en el campamento romano de Cidadela (Sobrado dos Monxes. Coruña). Memoria inédita Santiago, Dirección Xeral do Patrimonio Cultural, Consellería de Cultura e Turismo, Xunta de Galicia.

CAAmaño Gesto, J. M. 1997. Sondeos arqueológicos en la muralla del campamento romano de Cidadela. $\mathrm{Ga}$ llaecia, 16: 265-284

CAamaño Gesto, J. M.; Castro, I.; Ínsua, M ${ }^{\mathrm{a}}$ J.; López PÉreZ, M ${ }^{\mathrm{a}}$ C.; VÁZQUEZ, $\mathrm{M}^{\mathrm{a}}$ A. \& FERNÁNDEZ RODRÍGUEZ, C 2000. Evidencias materiales en el campamento romano de Cidadela -Sobrado dos Monxes, A Coruña-. In: V. OliveIRA Jorge (Ed.), Arqueología da Antigüedade na Península Ibérica, Actas do $3^{\circ}$ Congresso de Arqueología Peninsular (Vila Real, 1999), Porto, ADECAP: Vol. VI, 281-292.

CaAmaño Gesto, J. M. \& Fernández Rodríguez, C. 2002. Excavaciones en el campamento de Cidadela (A Coruña). Brigantium, 12: 199-207.

CAAmaño Gesto, J. M. \& Fernández RodRíGUEZ, C. 2006. Producción y comercialización en el campamento romano de Cidadela (Sobrado dos Monxes, A Coruña). In: Á. Morillo Cerdán (Ed.), Arqueología militar romana en Hispania II: Producción y abastecimiento en el ámbito militar, León, Servicio de publicaciones de la Universidad de León: 167-184

CABALlero Zoreda, L. 1996 El análisis estratigráfico de construcciones históricas. In: L. CABALLERO ZOREDA \& C. EsCRiBANo Velasco (Eds.), Arqueología de la Arquitectura. El método arqueológico aplicado al proceso de estudio y de intervención en edificios históricos, Salamanca, Europa Artes Gráficas: 55-74.

CABALLERO ZOREDA, L. 1995 Método para el análisis estratigráfico de construcciones históricas o "lectura de paramentos". Informes de la Construcción, 453: 37-46.

Carbajal Sobral, J. 1999. Los Concilios de Braga en los siglos VI y VII como reflejo de la vida en la Gallaecia de la época. Porriño: Imprenta Paz.

Carretero Vaquero, S. 1999. Objetos de hueso trabajado del campamento del ala II Flavia en Petavonium (Rosinos de Vidriales, Zamora). Lancia, 3: 49-72.

CARRETERo VAquero, S. 2000. El campamento romano del Ala II Flavia en Rosinos de Vidriales. La cerámica. Zamora: Instituto de Estudios Zamoranos 'Florián de Ocampo'.

Carretero Vaquero, S. \& Romero Carnicero, M. V. 1996. Los Campamentos Romanos de Petavonium (Rosinos de Vidriales, Zamora). Zamora: Fundación Rei Alfonso Henriques. 
Carro Otero, J. 1987. Moneda del rey D. Fernando II de Galicia-León y "ceca" compostelana, con el tema de la "Traslación" del cuerpo del Apostol Santiago (11571188). Compostellanum, XXXII (3-4): 575-594.

Castellanos, S. \& Martín Viso, I. 2005. The local articulation of central power in the north of the Iberian Peninsula. Early Medieval Europe, 13: 1-42.

Costa García, J. M. 2009. El exercitus hispanicus ante la encrucijada del siglo III. Gallaecia, 28: 151-166.

Costa García, J. M. 2010. Estudo de paramentos e análise das estruturas exhumadas na "pars nobilis" do campamento romano de A Cidadela (Sobrado dos Monxes, A Coruña). Gallaecia, 29: 191-201.

Costa García, J.M. 2013. Arqueología de los asentamientos militares romanos en la Hispania altoimperial (27 a.C. - ca. 280 d.C.). Tesis doctoral, Universidade de Santiago de Compostela.

COSTA GARCíA, J.M. 2014a. Datos para una reconstrucción integral del sistema defensivo del fuerte romano de A Cidadela (Sobrado dos Monxes, A Coruña). Sautuola, XVI-XVII: 163-177.

Costa GARCíA, J.M. 2014b. Las primeras intervenciones arqueológicas en A Cidadela (Sobrado dos Monxes, A Coruña). Gallaecia, 32: 109-127

Costa García, J. M. \& Varela Gómez, D. 2011. A Cidadela después de Roma. Introducción al estudio del yacimiento y su entorno durante el período medieval. Gallaecia, 30: 181-194.

Costa García, J. M.; Rodríguez Álvarez, E. \& VArela GómEZ, D. 2012. Del complejo militar romano al monacato altomedieval: aproximación a las transformaciones del espacio interior galaico entre los siglos I y X d. C. a partir de los asentamientos de A Cidadela (Sobrado dos Monxes, A Coruña). Estrat Critic, 5 (2): 454-464.

Criado BoAdo, F. \& GonzÁlez Méndez, M. (Coord.) 2003. Planear o Pasado. Ideas para a recuperación do Castro de Elviña. Galicia, Servicio de Publicacións da Universidade de Santiago de Compostela.

Díaz Martínez, P. C. 2011. El Reino Suevo. Madrid, Akal.

DíAZ Y DÍAZ, M. C. 1974. La vida de San Fructuoso de Braga. Estudio y edición crítica. Braga, Empresa do Diário de Minho.

Doval Galán, J. F. 1997. Los morteros del campamento de Cidadela. Gallaecia, 16: 285-300.

EAton, T. 2000. Plundering the past. Roman stonework in Medieval Britain. Stroud: Tempus.

FERNÁNDEZ FERNÁNDEZ, A. (2011). El comercio tardoantiguo (ss. IV-VII) en el Noroeste peninsular a través del registro arqueológico de la Ría de Vigo. Tesis doctoral, Universidade de Vigo.

Fernández Ochoa, C.; Gil Sendino, F.; Villar Calvo, A.; Fernández Rodríguez, N.; Álvarez ToleDO, G. \& MORÁN FERNÁNDEZ, O. 2005-2006. La villa romana de Veranes (Gijón, Asturias). Aportaciones preliminares sobre la transformación funcional del asentamiento en la tardía antigüedad. Cuadernos de prehistoria y Arqueología de la Universidad Autónoma de Madrid, 31-32: 137-194.

FERnÁndez Rodríguez, C. \& CAAMAÑo Gesto, J. M 1996. Memoria Técnica de Excavación en el cam- pamento romano de Cidadela (Sobrado dos Monxes. Coruña). Memoria inédita. Santiago, Dirección Xeral do Patrimonio Cultural, Consellería de Cultura e Turismo, Xunta de Galicia.

Freire CAMANIEL, J. 1989. ¿Un testimonio epigráfico de la existencia, en Orense, de un "Duque" de Leovigildo? Boletín Auriense, XVIII-XIX: 133-141.

Frighetto, R. 2006. Valério do Bierzo. Autobiografia. Noia, Toxosoutos.

GARCíA Y BELlido, A. 1968. Nueve estudios sobre la Legio VII Gemina y su campamento en León. León: Diputación Provincial.

GARCÍA Y BELLIDO, A. 1970. Estudios sobre la Legio VII Gemina y su campamento en León. In: A. VIÑAYO GONZÁLEZ (Ed.), Legio VII Gemina, León, Excma. Diputación Provincial: 569-599.

GonZÁlez FernándeZ, M. L. \& VidAl EnCINAS, J. M. 2005. Recientes hallazgos sobre el campamento de la Legio VII Gemina en León: la situación de los Principia y la configuración de los Latera Praetorii. BSAA Arq, LXXI: 161-184.

GonzÁlez MÉndez, M., Blanco-RoteA, R. 2011. Releyendo el pasado: nuevos resultados de la última intervención en el castro de Vigo (VigoPontevedra). In: RAMIL REgO, E. \& FERNÁNDEZ RodrígueZ, C. (Ed.), Actas del $2^{\circ}$ Congreso Internacional de Arqueoloxía de Vilalba. Férvedes, 7 Vilalba: 151-159.

GutiÉRREZ GonZÁleZ, J. A. 2011. Fortificaciones visigodas y conquista islámica del norte hispano (c. 711). In: L. A. García MORENo \& A. VigIL-EscalerA (Coord.), 711. Arqueología e Historia entre dos mundos. Madrid: Museo Arqueológico regional: 335-352.

JoHnson, A. 1983. Roman Forts of the 1st and 2nd centuries $A D$ in Britain and the German Provinces. London: Adam \& Charles Black.

LAMAS BÉRTOLO, J. 2008. Actuación arqueolóxica preventiva do proxecto do centro lúdico spa Parador de Turismo de Santo Estevo, Nogueira de Ramuín (Ourense). Actuacións arqueolóxicas, Ano 2006: 87-88.

LÓPEZ AlsinA, F. 1999. Parroquias y diócesis: el obispado de Santiago de Compostela. In: J. A. GARCÍA DE Cortázar (Ed.), Del Cantábrico al Duero. Trece estudios sobre organización social del espacio en los siglos VIII al XIII, Santander, Universidad de Cantabria: 263-312.

LÓPEZ PÉREZ, Mª C. 2006. La importación de terra sigillata en el campamento de Cidadela (Sobrado dos Monxes, A Coruña). In: Á. MoRILlo CERDÁN (Ed.), Arqueología militar romana en Hispania II: Producción y abastecimiento en el ámbito militar. León, Servicio de publicaciones de la Universidad de León: 432-437.

LÓPez PÉrez, M. C. \& CÉSAR VILA, M. 2009. La importación de Terra Sigillata durante la etapa tardorromana en la fachada atlántica del Noroeste peninsular. In: R. MARTíneZ \& M. CRESPO (Eds.), Metodología de Análisis Aplicada a los Estudios de Cerámica Tardoantigua y Medieval de la Península Ibérica, León, Ediciones Lobo Sapiens: 41-52.

LORING GARCÍA, M. I. 1987. Nobleza e iglesias propias en la Cantabria altomedieval. Studia histórica. Historia medieval, 5: 89-121. 
Análisis de la evolución constructiva de las estructuras excavadas en el yacimiento de A Cidadela (Sobrado dos Monxes, A Coruña) y propuestas interpretativas sobre sus "fases tardoantiguas"

Loscertales de Garcia de VAldeavellano, P. 1976 Tumbos del monasterio de Sobrado de los Monjes. Madrid, Dirección General del Patrimonio Artístico y Cultural, Archivo Histórico Nacional.

Mañana BorrazÁs, P.; Blanco RoteA, R. \& AyÁn Vila, X.M. 2002. Arqueotectura 1: Bases teóricometodológicas para una Arqueología de la Arquitectura. TAPA (Traballos de Arqueoloxía e Patrimonio), 25. Santiago de Compostela: LPPP, USC.

Morillo Cerdán, Á.; Pérez GonzÁlez, C. \& Illarregu Gómez, E. 2006. Herrera de Pisuerga (Palencia). Introducción histórica y arqueológica. Los asentamientos militares. In: $\mathrm{M}^{\mathrm{a}}$. P. GARCíA-BELLIDO (Ed.), Los campamentos romanos en Hispania (27 a.C.-192 d.C). El abastecimiento de moneda, Madrid: CSIC - Instituto Histórico Hoffmeyer - Instituto de Historia - Polifemo: 305-323.

NAVEIRO LÓPEZ, J. L. 1991. El comercio antiguo en el N.W. peninsular. A Coruña, Museo Arqueolóxico e Histórico.

PARENTI, R. 1995. Historia, importancia y aplicaciones del método de lectura de paramentos. Informes de la Construcción, 435: 19-29. Madrid: CSIC.

Quirós CAstillo, J. A. \& Fernández Mier, M. 2012. Para una historia social de la arquitectura monumental altomedieval asturiana. In: L. CABALLERO ZOREDA; P. Mateos CruZ \& C. García de CAStro VALDÉS (Coord.), Asturias entre visigodos y mozárabes: (Visigodos y Omeyas, VI - Madrid, 2010), Madrid, CSIC: 27-53

RAmIL GonzÁLEZ, E. 2006. Memoria Técnica de Excavación en el campamento romano de Cidadela (Sobrado dos Monxes. Coruña). Memoria inédita. Santiago, Dirección Xeral do Patrimonio Cultural, Consellería de Cultura e Turismo, Xunta de Galicia.

Ramil GonzÁLez, E. 2007. Memoria Técnica de Excavación en el campamento romano de Cidadela (Sobrado dos Monxes. Coruña). Memoria inédita. Santiago, Dirección Xeral do Patrimonio Cultural, Consellería de Cultura e Turismo, Xunta de Galicia.

RAmil GonzÁlez, E. 2008. Memoria Técnica de Excavación en el campamento romano de Cidadela (Sobrado dos Monxes. Coruña). Memoria inédita Santiago, Dirección Xeral do Patrimonio Cultural, Consellería de Cultura e Turismo, Xunta de Galicia.

RAmil GonzÁLEZ, E. 2009. Memoria Técnica de Excavación en el campamento romano de Cidadela (Sobrado dos Monxes. Coruña). Memoria inédita. Santiago, Dirección Xeral do Patrimonio Cultural Consellería de Cultura e Turismo, Xunta de Galicia.

Ramil GonzÁlez, E. 2010. Memoria Técnica de Excavación en el campamento romano de Cidadela (Sobrado dos Monxes. Coruña). Memoria inédita. Santiago, Dirección Xeral do Patrimonio Cultural, Consellería de Cultura e Turismo, Xunta de Galicia.
Ramil GonzÁlez, E. \& LóPez Loureiro, R. 2003. A Serra da Capelada: patrimonio arqueolóxico e patrimonio natural. Brigantium, 14: 23-37.

Ramil GonzÁlez, E.; Costa García, J. M. \& CAAmaño Gesto, J. M. 2013. Hornos hallados en el campamento romano de Cidadela (Sobrado dos Monxes, A Coruña). BSAA Arqueología 77-78: 269-290.

Rodríguez Colmenero, A. 2006a. Conjuntos arqueológico -estratigráficos definidores del urbanismo del campamento. In: A. RodRÍGUEZ COLMENERO \& S FERRER SIERRA (Eds.), Excavaciones arqueológicas en Aquis Ouerquennis. Actuaciones en el campamento romano (1975-2005), Lugo, Unión Fenosa - Grupo Arqueolóxico Larouco - Universidade de Santiago de Compostela - Fundación Aquae Querquennae-Vía Nova: 41-140.

RodríguEz COLMENERO, A. 2006b. Epigrafia, arte y materiales de construcción. Testimonios. In: A. RoDRÍGUEZ Colmenero \& S. FERRER SIERRA (Eds.), Excavaciones arqueológicas en Aquis Querquennis. Actuaciones en el campamento romano (19752005), Lugo, Unión Fenosa - Grupo Arqueolóxico Larouco - Universidade de Santiago de Compostela - Fundación Aquae Querquennae-Vía Nova: 141180

SÁnchez PARdo, J. C. 2013. Power and rural landscapes in early medieval Galicia (400-900 AD): towards a reincorporation of the archaeology into the historical narrative. Early Medieval Europe, 21 (2): 140-168.

SÁNCHEZ PARDO, J. C. 2014. Sobre las bases económicas de las aristocracias de la Gallaecia suevo-visigoda. Comercio, minería y articulación fiscal. Anuario de estudios medievales, 44/2, pp. 983-1023.

SÁnchez Pardo, J. C. \& Blanco-Rotea, R. 2014 Early Medieval Churches. History, Archeology and Heritage (2013-2017). Marie Curie EMCHAHE Project. The European Archaeologist, 42: 83-85.

SANJURJo SÁNCHEZ, J. 2012. Dating Bricks and Mortars of Ancient and Historical Buildings. In: S.M. RIVERA, A.L. PENA, (Eds). Brick and Mortar Research, New York, Novapublishers: 171-193

SANJURJo-SÁNCheZ, J.; TRINDAdE, M.J.; BlanCo-RoteA, R.; BENAVIDES GARCIA, R.; FERNÁNDEZ MOSQUERA, D.; BurbidGe, C.; PrudÊNCIO, M.I. \& DiAs, M.I. 2010. Chemical and mineralogical characterization of historic mortars from the Santa Eulalia de Bóveda temple, NW Spain. Journal of Archaeological Science, doi:10.1016/j.jas.2010.04.008: 2346-2351.

VÁZQUEZ MARTÍNEZ, Mª A. 2005. El vidrio de época roma na en la provincia de A Coruña. Tesis doctoral, Universidade de Santiago de Compostela.

Yzquierdo Perrín, R. 1993. Arte Medieval (I). A Coruña: Hércules. 